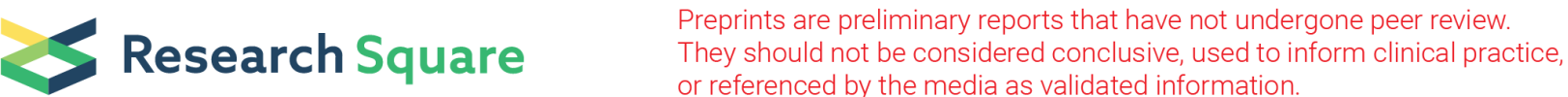

\section{Bi2S3 and MoS2 Soft Coatings: A Comparative Study of Their Frictional Behavior Under Different Humidity Levels, Contact Stresses, and Sliding Speeds}

\section{Bruno A. Pilotti ( $\sim$ bruno.pilotti@uns.edu.ar)}

Universidad Nacional del Sur https://orcid.org/0000-0003-2951-0103

\section{Germán Prieto}

Universidad Nacional del Sur Departamento de Ingenieria

\section{Alfredo Juan}

Universidad Nacional del Sur Departamento de Física: Universidad Nacional del Sur Departamento de Fisica

\section{Ricardo Faccio}

Universidad de la República Uruguay: Universidad de la Republica Uruguay

\section{Esteban Broitman}

SKF Research and Technology Development Center

\section{Mariana Dennehy}

Universidad Nacional del Sur

\section{Walter Tuckart}

Universidad Nacional del Sur Departamento de Ingenieria

\section{Research Article}

Keywords: Bismuth sulfide, Bi2S3, solid lubricants, soft coatings, ab initio calculations, DFT

Posted Date: February 25th, 2021

DOl: https://doi.org/10.21203/rs.3.rs-239639/v1

License: (c) (i) This work is licensed under a Creative Commons Attribution 4.0 International License. Read Full License

Version of Record: A version of this preprint was published at Tribology Letters on July 30th, 2021. See the published version at https://doi.org/10.1007/s11249-021-01486-y. 


\section{Abstract}

$\mathrm{Bi}_{2} \mathrm{~S}_{3}$ is a promising solid lubricant for demanding applications, such as oil extraction, heavy mining, and aerospace components. However, so far its tribological behavior has not been studied in depth. $\mathrm{Bi}_{2} \mathrm{~S}_{3}$ soft coatings were evaluated utilizing reciprocating sliding tests under different levels of relative humidity level, contact stress, and sliding speed and the results were benchmarked against $\mathrm{MoS}_{2}$ coatings. In addition, ab initio calculations using density functional theory modeling were employed for studying the interaction between the sulfides and the steel substrates and the effect of water intercalation at an atomic level. It was found that $\mathrm{Bi}_{2} \mathrm{~S}_{3}$ presents excellent environmental adaptability and substrate protection over a wide range of testing conditions, thanks to its characteristic crystal structure.

\section{Introduction}

In high demanding applications, such as oil extraction, mining equipment, or aerospace components, traditional lubrication using oils or greases is not suitable, due to the elevated contact stresses involved, high temperatures, low sliding speeds, high vacuum, and even radiation damage. In these kinds of environments, solid lubricants are often the only available choice for preventing excessive wear and reducing friction between sliding surfaces [1-5].

The field of solid lubrication is under constant evolution, with new materials emerging almost every day. There is a continuous effort to deepen the understanding of traditional solid lubricants, such as graphite and transition metal chalcogenides like $\mathrm{MoS}_{2}$, and to develop newer technologies as diamond-like carbon (DLC) [6], carbon fullerenes [7], and chameleon/adaptive coatings [8]. However, all solid lubricants exhibit some weaknesses. In particular, both graphite and transition metal chalcogenides (TMCs) heavily depend on the ambient conditions to properly lubricate.

A TMC with promising properties for being used as a solid lubricant is $\mathrm{Bi}_{2} \mathrm{~S}_{3}$. It has a layered crystal structure [9-11] that allows easy slip between the layers and can be considered as a "green" material due to its low toxicity $[12,13]$. Another advantage of this material is the existence of many reservoirs of natural $\mathrm{Bi}_{2} \mathrm{~S}_{3}$ (bismuthinite) around the world [14]. It also possesses attractive photo-electrical and semiconductor properties for the fabrication of sensors and solar cells $[15,16]$.

Bismuth-based compounds, in particular bismuth naphthenate, bismuth 2-ethyl hexanoate, bismuth dialkyl dithiocarbamate, and bismuth neodecanoate have been studied as extreme pressure (EP) additives in oils [17-20]. These compounds react with sulfur additives under the high pressures and temperatures that are developed in the contact zones to form a variety of by-products, such as bismuth sulfide, bismuth oxide, and metallic bismuth films [18-20]. Bismuth sulfides have also been studied by Müller et al. [21, 22] as additives in mineral oils and as a soft coating by González-Rodriguez et al. [13]. These studies reported promising results, but a systematic approach to the frictional response of pure $\mathrm{Bi}_{2} \mathrm{~S}_{3}$ under different conditions is still missing from the scientific literature, in particular regarding the influence of ambient humidity, contact stress, and sliding speed on the frictional behavior of $\mathrm{Bi}_{2} \mathrm{~S}_{3}$. 
Over the last 60 years, $\mathrm{MoS}_{2}$ has been considered the prototypic solid lubricant, with different uses as an additive in oils, greases, and coatings for a wide range of applications [23]. Its lubricant properties lie in its crystal structure, comprised of stacking of S-Mo-S atoms in a layered hexagonal layout. The bonds in the crystal unit are covalent and very strong in nature, while the layers are loosely bound to each other by weak Van der Waals forces. This configuration allows for easy slip when shear stress is applied. However, $\mathrm{MoS}_{2}$ requires relatively high contact pressures and low humidity environments to properly lubricate [2427], which limits its practical applications. When considering the influence of contact pressure, several studies confirmed experimentally that the $\mathrm{MoS}_{2}$ friction coefficient shows an inverse relationship with contact stress [28-30]. Similar results were reported by Liang et al. [31] and Onodera et al. [32, 33], in this latter case, using molecular dynamics simulations.

A better understanding of the operative lubricious mechanisms of $\mathrm{MoS}_{2}$ at an atomic level was achieved by Levita et al. [34] by using ab initio calculations. They reported that an increase in the applied load has a higher effect on the Pauli repulsion between the monolayers and favors the sliding between them. An approach based on ab initio calculations and molecular dynamics simulations performed by Levita and collaborators $[35,36]$ was employed to study the dependence of the friction coefficient of $\mathrm{MoS}_{2}$ under different atmospheres. The current understanding is that water molecules are physisorbed into the lattice of $\mathrm{MoS}_{2}$ through polar bonding between the sulfur atoms and the $\mathrm{H}_{2} \mathrm{O}$ molecules.

Similarly, Arif et al. [37] achieved the deconvolution of the influence of water and oxidation of ultrathin $\mathrm{MoS}_{2}$ coatings, reporting that water physisorbs in the form of a single layer on the top surfaces, increasing the friction. On the other hand, oxidized-MoS 2 showed increased friction and was more sensitive to the presence of humidity, as the material becomes more hydrophilic when sulfur atoms are substituted by oxygen. These results were also reported by Chow et al. [38] while studying the wettability of few-layers $\mathrm{WS}_{2}$ and $\mathrm{MoS}_{2}$ films. These are very important results as $\mathrm{MoS}_{2}$ films tend to oxidize using of thermochemical and tribochemical reactions [39].

Regarding the effect of sliding speed on the frictional response of $\mathrm{MoS}_{2}$, Wornyoh et al. [40] reported an inverse relationship between sliding speed and friction coefficient of $\mathrm{MoS}_{2}$ coatings generated by mechanical transfer between $\mathrm{MoS}_{2}$ pellets and a tungsten carbide pad.

Our research work aimed to study and compare the effect of different humidity levels, contact stresses, and sliding speeds on the frictional behavior of $\mathrm{Bi}_{2} \mathrm{~S}_{3}$ and $\mathrm{MoS}_{2}$ soft coatings. Preliminary theoretical studies have also been done to clarify the lubrication mechanisms and the differences in performance between the coatings.

\section{Materials And Methods \\ 2.1 Materials}


The $\mathrm{Bi}_{2} \mathrm{~S}_{3}$ was prepared using a simple aqueous synthesis. $\mathrm{Bi}\left(\mathrm{NO}_{3}\right)_{3} 5 \mathrm{H}_{2} \mathrm{O}$ (Aldrich) and a sulfur source were mixed in a surfactant aqueous dissolution, at mild conditions [41]. The $\mathrm{MoS}_{2}$ coatings were generated using a commercially available sulfide (Climax Molybdenum Co. - USA), with a purity level of $98 \%$.

The materials were characterized using a PANalytical Empyrean $3 \mathrm{x}$-ray diffractometer with $\mathrm{Ni}$-filtered CuKa radiation $(\lambda=1.541 \AA)$ and a PIXcel 3D detector. It was operated at a voltage of $45 \mathrm{kV}$ and a current of $35 \mathrm{~mA}$, in the $2 \Theta$ range from $10^{\circ}$ to $80^{\circ}$, using a continuous scan mode with a scan angular speed of $0.016^{\circ} \mathrm{min}^{-1}$. The morphology of the sulfides was evaluated by Scanning Electronic Microscopy using a Carl Zeiss EVO MA 10 equipped with an energy dispersion spectrometer Cambridge $x$-act. $\mathrm{Bi}_{2} \mathrm{~S}_{3}$ was also examined by Transmission Electron Microscopy using a JEM - 2100 HR microscope operated at $200 \mathrm{KV}$ of accelerating potential.

\subsection{Coatings preparation}

Due to the current state of understanding of the tribological properties of $\mathrm{Bi}_{2} \mathrm{~S}_{3}$ in the open literature, it was decided to produce the coatings by burnishing, as it is one of the simplest possible techniques for coating production. This kind of coatings facilitate the study of the frictional response of a solid lubricant, but they are not particularly durable. For this reason, the focus of this present work was placed on the evaluation of the frictional response of $\mathrm{Bi}_{2} \mathrm{~S}_{3}$ under different conditions for understanding the basic lubricity mechanisms of the material, while the durability and wear of $\mathrm{Bi}_{2} \mathrm{~S}_{3}$ soft coatings will be evaluated in a future stage.

The technique employed for obtaining the coatings consisted of polishing SAE 1045 steel disks of 45 $\mathrm{mm}$ in diameter with abrasive paper until grit 1000 in random directions. Afterward, the disks were cleaned with acetone in an ultrasonic bath for $10 \mathrm{~min}$. On top of the polished disks, $0.3 \mathrm{gr}$ of solid lubricant was placed and rubbed with a rotating disk covered with a polishing cloth for 60 minutes at 22 rpm and $30 \mathrm{MPa}$ of contact stress. Finally, the loose material was removed with dry compressed air.

The average roughness $(\mathrm{Ra})$ of the disks, determined with a Carl Zeiss Smartproof 5 laser confocal microscope, was $0.093 \pm 0.010 \mu \mathrm{m}$ with an isotropy value of the roughness pattern of $43 \%$. For determining the coating thickness, samples were prepared with the same methodology with a fraction of the disk surface covered with a piece of tape. After the burnishing process, the tape was carefully lifted and the step height between the steel substrate and the coating surface was measured using laser confocal microscopy.

\subsection{Tribological testing}

The frictional response of both coatings was evaluated by reciprocating sliding tests, which were performed with an Oscillating TRIBOtester (TRIBOtechnic, France), with a ball-on-flat configuration and equipped with an atmosphere chamber that allows the setting of the relative humidity content during the test. The tests were performed at different levels of relative humidity $(\mathrm{RH})$, ranging between 0 to $75 \% \mathrm{RH}$, 
and contact stresses, between 0.66 to $1.42 \mathrm{GPa}$. RH values of $43 \%, 60 \%$, and $75 \%$ were obtained by using saturated salt solutions of $\mathrm{K}_{2} \mathrm{CO}_{3}, \mathrm{NaBr}$, and $\mathrm{NaCl}$, respectively [42]. The $\mathrm{RH}=22 \%$ was the laboratory humidity condition, and $\mathrm{RH}=0 \%$, was reached by filling the chamber with dry nitrogen at $1 \mathrm{~atm}$. This latter setup was chosen based on the results reported by Zhao and collaborators [27], where they found that there are no significant differences in the performance of $\mathrm{MoS}_{2}$ coatings when tested in nitrogen or air atmosphere when the relative humidity is below $10 \%$. Additionally, the sliding speed was varied between 5 and $50 \mathrm{~mm} / \mathrm{s}$.

The friction force was continuously measured during the tests and a coefficient of friction (CoF) values above 0.3 were considered as a signal of coating failure. The track length was $5 \mathrm{~mm}$ with a total sliding distance of $10 \mathrm{~m}$. Each test was repeated at least three times. The counterparts were AISI 52100 steel balls with a diameter of $6.35 \mathrm{~mm}$, an average roughness $(\mathrm{Ra})$ of $0.02 \mu \mathrm{m}$, and a hardness of $60 \mathrm{HRC}$. The balls were cleaned with acetone in an ultrasonic bath for 10 minutes before testing. After the tests, both the tracks and the counterparts were examined with optical and scanning electron microscopy equipped with energy dispersive spectroscopy.

\subsection{Ab initio calculations}

The experimental results were complemented with first principles Density Functional Theory (DFT) calculations $[43,44]$. The theoretical calculations were performed in order to better understand the lubricating mechanisms and different interactions of the coatings at an atomic level. In particular, we analyzed the interactions between the sulfides and the Fe substrates and the influence of the addition of water molecules between sulfide layers. Similar calculations were performed using $\mathrm{MoS}_{2}$ by numerous authors like Levita et al. and Khare et al. [34, 35, 45-47] which were used as a benchmark to compare and discuss the results obtained in this present work regarding $\mathrm{Bi}_{2} \mathrm{~S}_{3}$.

The code used for the calculations was the Vienna ab initio simulation package (VASP) $[48,49]$. The applied pseudopotentials were set with a plane-wave base utilizing the projector augmented wave (PAW) method $[49,50]$ using GGA as the exchange-correlation functional according to the Perdew-BurkeErnzerhof (PBE) model [51]. An energy cutoff of $400 \mathrm{eV}$ was used to expand the Kohn-Sham orbitals into the plane-wave basis set. The k-point mesh was taken equivalent to $6 \times 6 \times 1$ for the full (reducible) Brillouin Zone for all calculations. The structures were optimized until the forces in all the atoms were lower than the tolerance of $0.01 \mathrm{eV} / \AA$, and the unit cell was optimized until the components of the stress tensor were lower than $1 \mathrm{kBar}$.

\section{Results And Discussion}

\subsection{Characterization of solid lubricant particles and coatings}


The morphology of the sulfides is presented in Fig. 1. Scanning electron microscopy of the $\mathrm{Bi}_{2} \mathrm{~S}_{3}$ shows spherical agglomerations ranging between 300 to $500 \mathrm{~nm}$ in diameter composed of nanorods. A more detailed examination using TEM of these nanorods is shown in Fig. 2, where it can be seen that the nanorods have a uniform size distribution, with average diameters of $10 \mathrm{~nm}$ and lengths ranging between 40 to $100 \mathrm{~nm}$. The material also exhibited a high degree of crystallinity, with a fringe width of $0.54 \mathrm{~nm}$. That value corresponds to the d-spacing of the (200) planes of the $\mathrm{Bi}_{2} \mathrm{~S}_{3}$ orthorhombic structure and follows the results reported by Panigrahi et al. [52].

The analysis of the $\mathrm{MoS}_{2}$ shows equiaxial blocks of sheets, with an average length/width ranging between 3 to $8 \mu \mathrm{m}$ and a thickness in the order of 500 to $700 \mathrm{~nm}$, as can be seen in Fig. 1b. The thickness of the individual $\mathrm{MoS}_{2}$ sheets varies between 40 to $60 \mathrm{~nm}$, as this is the typical morphology for this kind of commercial-grade sulfide.

The XRD spectrum of the $\mathrm{Bi}_{2} \mathrm{~S}_{3}$ is shown in Fig. 3a. The position and relative intensity of the diffraction peaks matches with the crystallographic reference card for the orthorhombic crystal structure of $\mathrm{Bi}_{2} \mathrm{~S}_{3}$ (JCDS N $\left.{ }^{\circ} 17-0320\right)$. Figure $3 b$ shows the XRD spectrum of the $\mathrm{MoS}_{2}$ particles, along with the crystallographic reference (JCDS N $\left.{ }^{\circ} 37-1492\right)$, confirming the hexagonal crystal structure of the material.

The morphology of the coatings before testing is presented in Fig. 4, in which it can be seen a porous surface, with loosely bound agglomerations of sulfide particles in both cases. This morphology is typical of burnished coatings. The coatings thicknesses were determined by laser confocal microscopy, with an average value of $8.7 \pm 1.1 \mu \mathrm{m}$ for both $\mathrm{Bi}_{2} \mathrm{~S}_{3}$ and $\mathrm{MoS}_{2}$ coatings.

\subsection{Tribological tests}

\subsubsection{Influence of relative humidity on the friction behavior}

Figure 5 shows the evolution of the friction coefficient during reciprocal tests with variable values of $\mathrm{RH}$ in the tribometer chamber. The $\mathrm{Bi}_{2} \mathrm{~S}_{3}$ coatings had a stable behavior (Fig. $5 \mathrm{a}$ ) with humidity contents ranging between 0 and $43 \%$, showing no significant influence from the water content in the atmosphere. At those $\mathrm{RH}$ levels, the CoF leveled at 0.13 , being relatively constant during the whole test. However, when tested at $75 \%$ of $\mathrm{RH}, \mathrm{Bi}_{2} \mathrm{~S}_{3}$ coatings failed by spalling and detachment from the substrate, leading to a rapid increase in friction. However, a brief low CoF region can be seen during the first $2 \mathrm{~m}$ of sliding, with a CoF value of ca. 0.12 , very similar to the observed during the steady-state regions of tests at 0,22 , and $43 \%$ of $\mathrm{RH}$. It is devised that the coating had some lubricating capacity but the conditions were too harsh and led to the failure of the coating. To further analyze this behavior, tests at an additional intermediate $\mathrm{RH}$ level of $60 \%$ were performed, in which it could be seen that the CoF remained stable during the first 5 $\mathrm{m}$ of sliding but at a higher value of 0.16 . After this initial stable region, it can be seen that friction increased continuously until the rest of the test, finishing at values around 0.22 . 
We hypothesize that for a given set of sliding conditions, such as contact stress and sliding speed, the humidity content diminishes the durability of the coating but it has no significant effect on the friction coefficient. Further characterization of this behavior will be made in our future research stage. It should be noted that the authors could not find references in the open literature regarding the influence of relative humidity on the frictional response of $\mathrm{Bi}_{2} \mathrm{~S}_{3}$ coatings.

In contrast, $\mathrm{MoS}_{2}$ coatings have shown the typical behavior of this material, increasing relative humidity produced an increase in the CoF [53], ranging from an average CoF of 0.1 at $0 \%$ of $\mathrm{RH}$ up to 0.2 at $75 \%$ $\mathrm{RH}$ (Fig. 5b). In addition, $\mathrm{MoS}_{2} \mathrm{CoF}$ becomes erratic and variable at high humidity levels, in contrast to a very stable behavior when tested in a dry atmosphere. The $\mathrm{MoS}_{2}$ coatings friction values at different humidity levels are in accordance with previous results available in the literature, e.g. the reports of Fusaro [54], Scharf et al. [53], Donnet et al. [29], Khare et al. [46], and Serpini et al. [26]. In particular, Khare and Burris [46] found that the friction of $\mathrm{MoS}_{2}$ at ambient temperatures depends on both the amount of water in the environment and on the diffused water in the bulk. Friction increase at high humidity levels could be related to the bond of the $\mathrm{H}_{2} \mathrm{O}$ molecules to the sulfur atoms or edge sites. Further discussion of this mechanism is presented in Sect. 3.4.2.

\subsubsection{Influence of the contact stress on the friction behavior}

Both the $\mathrm{Bi}_{2} \mathrm{~S}_{3}$ and the $\mathrm{MoS}_{2}$ (Figs. 6a and b) coatings showed an inverse relationship between friction coefficient and contact stress, but $\mathrm{Bi}_{2} \mathrm{~S}_{3}$ was significantly less sensitive to changes in contact stress. $\mathrm{Bi}_{2} \mathrm{~S}_{3}$ exhibited average CoF values between and 0.17 at $0.6 \mathrm{GPa}$ and 0.12 at $1.2 \mathrm{GPa}$, representing a $29 \%$ decrease in friction within the considered contact stress interval.

When analyzing the behavior of the $\mathrm{Bi}_{2} \mathrm{~S}_{3}$ coating at the maximum testing contact stress of $1.4 \mathrm{GPa}$, it could be observed that during the first $3 \mathrm{~m}$ of sliding the CoF remained stable at a value of 0.12 . After this point, friction quickly raised, signaling the failure of the coating. The failure mechanism is further discussed in Sect. 3.3, while the influence of contact stress on the durability of $\mathrm{Bi}_{2} \mathrm{~S}_{3}$ coatings will be studied in detail in future research work.

On the other hand, the frictional response of $\mathrm{MoS}_{2}$ coatings was more sensitive to changes in the contact stress, ranging from CoF values of 0.22 at $0.6 \mathrm{GPa}$ to 0.08 at $1.4 \mathrm{GPa}$ ( $63 \%$ of CoF reduction). The behavior of the $\mathrm{MoS}_{2}$ coatings with increasing contact stress is consistent with the results reported in the literature by, e.g. Singer et al. [28], Kohli et al. [30], and Scharf et al. [55], while no results regarding this relationship in the case of $\mathrm{Bi}_{2} \mathrm{~S}_{3}$ could be found in the open literature. However, it is hypothesized that the lower reduction in friction coefficient with increasing contact stress in $\mathrm{Bi}_{2} \mathrm{~S}_{3}$ can be related to its more complex crystal structure in comparison to $\mathrm{MoS}_{2}$, which has $\mathrm{Bi}$ atoms exposed that can interact with the $S$ atoms of other layers. These attractive bonds compete with the repulsion generated from the $S \cdots S$ bonds that generate when the sulfide layers are closer together due to the increase in contact stress. In 
the case of $\mathrm{MoS}_{2}$, its compact crystal structure favors the repulsion between the $\mathrm{S}$ atoms of each layer that increase the electrostatic repulsion between the layers when the contact stress is increased [34].

\subsubsection{Influence of the sliding speed on the friction behavior}

Figures $7 a$ and $b$ show the CoF records for both sulfide coatings with different test speeds, ranging from 5 to $50 \mathrm{~mm} / \mathrm{s}$. In this case, $\mathrm{Bi}_{2} \mathrm{~S}_{3}$ had the opposite behavior in comparison to $\mathrm{MoS}_{2}$, i.e. its friction coefficient was proportional to the sliding speed, while $\mathrm{MoS}_{2}$ showed an inverse relationship. The CoF of the $\mathrm{Bi}_{2} \mathrm{~S}_{3}$ coatings increased by approximately $50 \%$ between 5 and $50 \mathrm{~mm} / \mathrm{s}$, while the friction records showed a monotonically decreasing value as the tests progressed (Fig. 7a). It is inferred that this direct relationship between friction and sliding speed could be related to the crystal structure of $\mathrm{Bi}_{2} \mathrm{~S}_{3}$, as $\mathrm{Bi}$ atoms are exposed and interact with the $S$ atoms of the other layers in relative motion, thus impairing the electrostatic repulsion between the $S$ atoms of each layer, increasing friction.

On the contrary, the $\mathrm{MoS}_{2}$ coatings friction coefficient decreased with increasing sliding speeds by $25 \%$, with a very erratic CoF record at $5 \mathrm{~mm} / \mathrm{s}$ (Fig. $7 \mathrm{~b}$ ). In this latter case, friction showed its lowest value (CoF $\sim 0.15$ ), which increased during the test until reaching a CoF value of 0.2 . The behavior of the $\mathrm{MoS}_{2}$ coatings at higher speeds ( 20 and $50 \mathrm{~mm} / \mathrm{s}$ ) was quite similar in both cases, showing a running-in period with an increasing CoF until approximately $4 \mathrm{~m}$ of sliding and then the trend reversed and CoF diminished until reaching values between $0.15-0.17$. This reduction of friction with increasing sliding speed could be related to a local increase of temperature in the contact zone that contributed to water desorption from the coating, thus improving its frictional response. The observed relationship between the friction coefficient and the sliding speed is similar to the results reported by Wornyoh et al. [40].

\subsubsection{Summary of tribological testing}

A summary of the friction results is presented in Fig. 8, using a modified box-plot graph. This type of graph was chosen to facilitate the comparison between datasets and displays the median, the values between the Q1 and Q3 quartiles (box height), and the data range without outliers. Figure 8a shows that the response of $\mathrm{Bi}_{2} \mathrm{~S}_{3}$ is very stable, without significant differences between the median friction values for relative humidity levels of 0,22 , and $43 \%$, as well as the box heights. With increasing humidity level, it can be seen that the median and both the upper limit of the boxes and the top whiskers exhibit higher values and an upward tendency of the friction values. In comparison, both the median value and the box height for $\mathrm{MoS}_{2}$ increases with increasing humidity content, showing no stable regions in terms of frictional response.

Figures $8 \mathrm{~b}$ and e clearly show the inverse relationship between the friction coefficient and the applied contact stress for both $\mathrm{Bi}_{2} \mathrm{~S}_{3}$ and $\mathrm{MoS}_{2}$. However, $\mathrm{Bi}_{2} \mathrm{~S}_{3}$ has a more stable CoF value at contact stresses below $1.2 \mathrm{GPa}$, as both the box heights and the whiskers lengths are very small in comparison to the ones 
corresponding to $\mathrm{MoS}_{2}$. Also, $\mathrm{Bi}_{2} \mathrm{~S}_{3}$ presents a lower variation in the median value of CoF as a function of the applied contact pressure.

Finally, Figs. $8 \mathrm{c}$ and $\mathrm{f}$ present the different behaviors of the sulfides regarding the variations in sliding speed. $\mathrm{Bi}_{2} \mathrm{~S}_{3}$ shows a proportional relationship between friction coefficient and sliding speed, while the opposite behavior can be seen in the case of $\mathrm{MoS}_{2}$. Again, the dispersion of the values corresponding to $\mathrm{Bi}_{2} \mathrm{~S}_{3}$ is lower than $\mathrm{MoS}_{2}$.

\subsection{Wear surfaces characterization}

Wear surfaces were analyzed after testing at $0.6 \mathrm{GPa}$ of contact stress and $22 \%$ of relative humidity and $10 \mathrm{~m}$ of sliding distance. SEM examination of the wear tracks (Fig. 9) revealed that the $\mathrm{Bi}_{2} \mathrm{~S}_{3}$ coatings successfully endured these testing conditions and remained in the wear track after the completion of the test, thus preventing direct metal-to-metal contact. However, the surface of the coating in the track region presented cracks and signs of incipient spalling. When analyzing the counterpart (Fig. 10) it was found that no transfer film was formed and no signs of significant damage could be observed on the surface.

The SEM-EDS characterization of the $\mathrm{MoS}_{2}$ coated specimen is presented in Fig. 11. It can be seen that no significant amounts of $\mathrm{MoS}_{2}$ were detected in the wear track as the material was transferred to the counterpart, forming a transfer film with high adherence that reduced the friction, as shown in Fig. 12. This mechanism is typical of $\mathrm{MoS}_{2}$ lubrication, as also described by Singer et al. [28,56,57], Donnet et al. [29], Levita et al. [34], and Kohli [30]. However, slight scratches in the direction of sliding were found in the disk surface, meaning that the $\mathrm{MoS}_{2}$ coating did not prevent direct contact between the metal surfaces.

\subsection{Theoretical Calculations \\ 3.4.1 The interface model}

A simplified interface model is proposed in this present work, consisting of monolayers of sulfides interacting with the SAE 52100 steel counterpart. The SAE 52100 steel from the ball was modeled with a bulk iron BCT unit cell with lattice parameters of $a=b=2.085 \AA$ and $c=2.980 \AA(c / a=1.045)$ taken from [58]. The optimized lattice parameter of a perfect $\mathrm{MoS}_{2}$ hexagonal monolayer resulted to be $a=b=3.183$ $\AA$ and $\mathrm{Y}=120^{\circ}$, which is very close to the reported experimentally and theoretically $[59,60]$. The $\mathrm{Bi}_{2} \mathrm{~S}_{3}$ (010) orthorhombic monolayer was constructed from the crystal structure data of Łukaszewicz et al. [10], with $a=11.920 \AA, b=4.040 \AA$. A vacuum space of $10 \AA$ was generated to model and consider the monolayers of both $\mathrm{MoS}_{2}$ and $\mathrm{Bi}_{2} \mathrm{~S}_{3}$ with the iron counterpart.

The interface was built by stacking 7 layers of Fe BCT (110) to form a slab. The $\mathrm{MoS}_{2}(001)$ and the $\mathrm{Bi}_{2} \mathrm{~S}_{3}(010)$ monolayers were put on top of this slab separately, as shown in Fig. 13. Since the crystalline system of $\mathrm{MoS}_{2}$ is different from the one of $\mathrm{Bi}_{2} \mathrm{~S}_{3}$, a unit cell transformation was performed to obtain a 
better model for the adsorption description, and thus to minimize the lattice mismatch. In the case of $\mathrm{MoS}_{2}(001) / \mathrm{Fe} \mathrm{BCT}(110)$ a supercell with rotation was applied to get the final lattice parameters of $\mathrm{a}=\mathrm{b}$ $=5.022 \AA$ and $\gamma=107^{\circ}$. In the case of $\mathrm{Bi}_{2} \mathrm{~S}_{3}(010) / \mathrm{Fe} \mathrm{BCT}$ (110), another supercell transformation was applied, including rotation, to reach the final lattice parameters of $a=11.920 \AA, b=4.042 \AA$, and $y=90^{\circ}$. Both systems were allowed to relax considering the $\mathrm{MoS}_{2}(001)$ and $\mathrm{Bi}_{2} \mathrm{~S}_{3}(010)$ monolayers and the two outmost Fe layers of Fe (BCT) (110).

The adhesion energy $\left(E_{a d h}\right)$ was defined as follows:

$\mathrm{E}_{\mathrm{adh}}(\mathrm{eV})=\mathrm{E}_{\text {monolayer/Fe }}(\mathrm{eV})-\mathrm{E}_{\text {monolayer }}(\mathrm{eV})$

Where "monolayer" represents $\mathrm{MoS}_{2}(001)$ or $\mathrm{Bi}_{2} \mathrm{~S}_{3}(010)$ and "monolayer/Fe" the corresponding multilayer.

Figure 13 shows a side view of both interfaces after optimization. In the case of $\mathrm{Bi}_{2} \mathrm{~S}_{3}$ less $\mathrm{S}$ atoms are connected with the metal surface and the Fe-S bond distances fall in the range 2.13 to $2.33 \AA$. For $\operatorname{MoS}_{2}$, there are more sulfur atoms close to the surface with Fe-S bond distances from 2.19 to $2.36 \AA$. The lattice distortion is higher in the case of $\mathrm{MoS}_{2}$ due to a higher lattice mismatch. Even though the difference in surface adhesion energy is small (about $0.005 \mathrm{eV} / \AA^{2}$ ), there is a significant difference in the number of effective Fe-S bonds. $\mathrm{Bi}_{2} \mathrm{~S}_{3}$ presents 7 bonds in a unit cell of $48.2 \AA^{2}\left(0.15\right.$ bonds/ $\left./ \AA^{2}\right)$, while $\mathrm{MoS}_{2}$ shows 6 bonds in a unit cell of $24.1 \AA^{2}\left(0.25\right.$ bonds $\left./ \AA^{2}\right)$ representing a $66 \%$ difference in the number of bonds per surface unit. This difference is attributed to the crystal structure of $\mathrm{MoS}_{2}$, which has $\mathrm{S}$ atoms on its whole surface, while $\mathrm{Bi}_{2} \mathrm{~S}_{3}$ has some $\mathrm{Bi}$ atoms exposed that do not form bonds with the Fe atoms of the slab.

Although our interface model is very simplified, it is inferred that the similar values of surface adhesion energies between the two sulfides explains their ability to form coatings on steel surfaces, while the absence of transfer films in the case of $\mathrm{Bi}_{2} \mathrm{~S}_{3}$ coatings (Fig. 10) is attributed to its lower bonding density.

\subsubsection{Influence of $\mathrm{H}_{2} \mathrm{O}$}

As a first approach to model the behavior of the coatings under different relative humidity levels, a setup comprising the interaction of two independent sulfide layers were built, in which the lower layer was fixed while the upper one was able to move freely in the $c$ axis (Fig. 14). The initial distance between the layers was chosen from the equilibrium geometry from the pristine structure of the sulfides and the final system 's energy was calculated, denoted as $\mathrm{E}_{\mathrm{D}}$. This setup was repeated with an initial distance between the layers twice the value of the first set of measurements, to evaluate the equilibrium positions of the layers starting at different initial distances. In this case, the energy of the system was denoted as $E_{2 D}$.

To assess the change in the system energy and to estimate how difficult is to separate one layer from another, a separation energy variation $\left(\Delta \mathrm{E}_{\mathrm{sep}}\right)$ parameter was defined as follows: 
$\Delta \mathrm{E}_{\text {sep }}(\mathrm{eV})=\mathrm{E}_{2 \mathrm{D}}(\mathrm{eV})-\mathrm{E}_{\mathrm{D}}(\mathrm{eV})$

Where:

- $E_{D}$ : Total energy of the system starting from the equilibrium position of the sulfide layers.

- $E_{2 D}$ : Total energy of the system with an initial distance of the layers twice the corresponding to the equilibrium distance of the pristine layers.

An increase in the value of $\Delta \mathrm{E}_{\text {sep }}$ means that more energy is needed to separate the layers and thus can be roughly related to the ability to shear one layer against another. As the layers of $\mathrm{Bi}_{2} \mathrm{~S}_{3}$ and $\mathrm{MoS}_{2}$ have different sizes, this variation in energy is normalized in terms of the transversal area of each sulfide layer. In the first stage of analysis, in which no $\mathrm{H}_{2} \mathrm{O}$ molecules were added to the system, it was found that the value of $\Delta \mathrm{E}_{\text {sep }}$ of $\mathrm{Bi}_{2} \mathrm{~S}_{3}$ is $47 \%$ higher than the corresponding to $\mathrm{MoS}_{2}$. Also, it can be seen in Fig. 14 that the crystal structure of $\mathrm{Bi}_{2} \mathrm{~S}_{3}$ has exposed metallic atoms on its surface, thus generating shorter and therefore stronger van der Waals bonds between the layers. It is inferred that these interactions could increase the friction force between sliding $\mathrm{Bi}_{2} \mathrm{~S}_{3}$ layers under some conditions. In the case of $\mathrm{MoS}_{2}$, the layers have $S$ atoms in their whole surface, generating electrostatic repulsion between the layers. In a detailed study, Levita and collaborators [34] have reported that these interactions between $S$ atoms in $\mathrm{MoS}_{2}$ layers are responsible for its low friction coefficient.

In the second stage of analysis, up to four $\mathrm{H}_{2} \mathrm{O}$ molecules were incorporated into the supercell systems. The $\mathrm{H}_{2} \mathrm{O}$ molecules were added into the interlayer space between the layers and were allowed to freely move without any restrictions. Then, the equilibrium positions of both the water molecules and the sulfide layers were determined. Again, the upper layers were able to move freely in the c-axis. This setup was modeled with the layers starting from the equilibrium distance of the pristine supercells (Fig. 15) and repeated with twice the initial distance (Fig. 1 of the Online Supplementary Material). It should be noted that these representations display a transversal view of the system and, as the $\mathrm{H}_{2} \mathrm{O}$ molecules can move freely in the 3 dimensions, in some cases they can be left out of the viewing plane.

After reaching the equilibrium, the values of $\Delta \mathrm{E}_{\text {sep }}$ of the systems and the minimum distance between $\mathrm{S}$ atoms between the layers were calculated. It can be seen in Fig. 16 that $\mathrm{Bi}_{2} \mathrm{~S}_{3}$ shows very little variation in the $\Delta \mathrm{E}_{\text {sep }}$ values with different amounts of $\mathrm{H}_{2} \mathrm{O}$ molecules added to the system, being the maximum difference concerning the base condition of $21 \%\left(0.038 \mathrm{vs} .0 .030 \mathrm{eV} / \AA^{2}\right)$, while for $\mathrm{MoS}_{2}$, this variation is $65 \%$ ( 0.026 vs. $\left.0.009 \mathrm{eV} / \AA^{2}\right)$. Additional information and results can be found in Table 1 of the Online Supplementary Material.

Additionally, it can be seen in Fig. 15 that the more complex crystal structure of $\mathrm{Bi}_{2} \mathrm{~S}_{3}$ allows for the separation of the $\mathrm{H}_{2} \mathrm{O}$ molecules from each other, thus generating less distance between the sulfide layers with increasing amounts of $\mathrm{H}_{2} \mathrm{O}$ molecules in comparison to $\mathrm{MoS}_{2}$. The minimum distance between S atoms from each layer (indicated as "S-S Distance" in Fig. 15) was plotted against the number 
of added $\mathrm{H}_{2} \mathrm{O}$ molecules and presented in Fig. 17. It can be observed that $\mathrm{Bi}_{2} \mathrm{~S}_{3}$ accounts for a maximum of $76 \%$ increase in the S-S distance when 4 molecules of $\mathrm{H}_{2} \mathrm{O}$ were added, while $\mathrm{MoS}_{2}$ exhibits a monotonically increasing trend, with an increase of $\sim 100 \%$ of the initial separation distance between monolayers with the addition of four $\mathrm{H}_{2} \mathrm{O}$ molecules. Even though the presented model is a strong simplification and has obvious limitations, it can be inferred from the ab initio calculations that the characteristic crystal structure of $\mathrm{Bi}_{2} \mathrm{~S}_{3}$ makes it less sensitive to variations in the humidity content in the atmosphere, as seen in the reciprocating tests under variable humidity in Fig. 5.

A detailed analysis of the equilibrium positions of the supercell systems shows significant differences in the interaction of $\mathrm{H}_{2} \mathrm{O}$ molecules with each type of sulfide, as can be seen in the close-up view of the systems at the equilibrium positions with the addition of three $\mathrm{H}_{2} \mathrm{O}$ molecules (Fig. 18). For clarity purposes, the different interactions between the atoms have been labeled and highlighted with green discontinuous lines. It should be taken into account that as the $\mathrm{H}_{2} \mathrm{O}$ molecules can move freely in the three dimensions, they can be left out of the transversal plane selected for the representation. It can be seen that in the case of $\mathrm{Bi}_{2} \mathrm{~S}_{3}$, the $\mathrm{H}_{2} \mathrm{O}$ molecules have oriented to form $\mathrm{S} \cdots \mathrm{H}$ bonds and also O-Bi bonds with the $\mathrm{Bi}$ atoms that are exposed from the sulfide layer. This latter phenomenon reduces the distance between layers and thus induces stronger $\mathrm{S} \cdots \mathrm{H}$ interactions that generate electrostatic repulsion between the layers. These interactions compete with the formation of lateral $\mathrm{S} \cdots \mathrm{H}$ bonds that tend to induce adhesion between the sulfide layers. In the case of $\mathrm{MoS}_{2}$, it can be seen that the $\mathrm{H}_{2} \mathrm{O}$ molecules formed clusters bonded by hydrogen bridges and remained at the middle point between the sulfide layers. Also, the water molecules rotated to form $\mathrm{S} \cdots \mathrm{H}$ bonds that can impair the electrostatic repulsion between the $\mathrm{S}$ atoms of each layer. These results are in accordance with those reported by Levita and collaborators [34, 35] where it was demonstrated that the formation of these $\mathrm{S} \cdots \mathrm{H}$ bonds increases the energy required to generate a shearing displacement between $\mathrm{MoS}_{2}$ layers.

\section{Conclusions}

Based on the results obtained from the study of the frictional behavior of $\mathrm{Bi}_{2} \mathrm{~S}_{3}$ soft coatings under different relative humidity levels, contact stresses, and sliding speeds, we conclude that:

- $\mathrm{Bi}_{2} \mathrm{~S}_{3}$ can bond to steel surfaces, forming lubricant coatings that reduce friction and prevent wear under a wide range of humidity contents, contact stresses, and sliding speeds. Contrary to $\mathrm{MoS}_{2}$, $\mathrm{Bi}_{2} \mathrm{~S}_{3}$ does not form transfer films due to its lower bond density with Fe.

- The frictional response of $\mathrm{Bi}_{2} \mathrm{~S}_{3}$ is less affected by variations in both relative humidity and contact stress in comparison to $\mathrm{MoS}_{2}$, while a slight increase in the friction coefficient with increasing sliding speed was observed for $\mathrm{Bi}_{2} \mathrm{~S}_{3}$.

- The differences in the frictional behaviors between $\mathrm{Bi}_{2} \mathrm{~S}_{3}$ and $\mathrm{MoS}_{2}$ are attributed to their different crystal structures. The use of DFT modeling was helpful to deepen the understanding of the lubricity mechanisms of $\mathrm{Bi}_{2} \mathrm{~S}_{3}$ at the atomic level and the influence of humidity in its frictional behavior. The 
particular crystal structure of $\mathrm{Bi}_{2} \mathrm{~S}_{3}$ prevents the formation of large clusters of $\mathrm{H}_{2} \mathrm{O}$ molecules that impair the electrostatic repulsion between sulfide layers and increases friction by the formation of S...H bonds.

- Bi2S3 is a promising candidate for the development of self-lubricated coatings thanks to its adaptability to different environmental conditions and low toxicity.

\section{Declarations}

\section{Acknowledgements}

The authors wish to express their appreciation for the funding given by the Agencia Nacional de Promoción Científica y Tecnológica in the form of the Grant ANPCYT PICT-2017-1316.

\section{Funding}

The research leading to these results received funding from the Agencia Nacional de Promoción Científica y Tecnológica in the form of the Grant ANPCYT PICT-2017-1316.

\section{Conflicts of interest}

The authors do not have any conflict of interests.

Availability of data and material Not applicable

Code availability Not applicable

\section{Authors' contributions}

Methodology: Bruno A. Pilotti, Germán Prieto, Alfredo Juan.

Investigation: Bruno A. Pilotti, Germán Prieto, Ricardo Faccio, Esteban Broitman.

Writing - Original Draft: Bruno A. Pilotti, Germán Prieto, Ricardo Faccio.

Writing - Review \& Editing: Mariana Dennehy, Alfredo Juan, Esteban Broitman

Data Curation: Mariana Dennehy, Alfredo Juan.

Resources: Mariana Dennehy, Ricardo Faccio, Esteban Broitman.

Conceptualization: Walter Tuckart

Visualization: Walter Tuckart

Supervision: Walter Tuckart 
Project administration, Funding acquisition: Walter Tuckart

Ethics approval Not applicable

Consent to participate Not applicable

Consent for publication Not applicable

\section{References}

[1] T. Castiñeiras, A. Núñez, E. Gallo, G. Carcagno, Dry dope-free OCTG connections: A novel environmentally friendly technology validated through diverse and severe field conditions, SPE/IADC Drill. Conf. Proc. 2 (2009) 879-890. https://doi.org/10.2118/119642-ms.

[2] A. Leech, A. Roberts, Development of premium threaded connections for casing and tubing, SPE Drill. Complet. 22 (2007) 106-111. https://doi.org/10.4028/www.scientific.net/AMR.744.53.

[3] K. Miyoshi, Solid Lubricants and Coatings for Extreme Environments: State-of-the-Art Survey, Nasa Tm2007-214668. (2007) 1-23. https://doi.org/20070010580.

[4] O. Gohardani, M.C. Elola, C. Elizetxea, Potential and prospective implementation of carbon nanotubes on next generation aircraft and space vehicles: A review of current and expected applications in aerospace sciences, Prog. Aerosp. Sci. 70 (2014) 42-68. https://doi.org/10.1016/j.paerosci.2014.05.002.

[5] C. Donnet, A. Erdemir, Solid lubricant coatings: Recent developments and future trends, Tribol. Lett. 17 (2004) 389-397. https://doi.org/10.1023/B:TRIL.0000044487.32514.1d.

[6] A. Erdemir, J.M. Martin, Superior wear resistance of diamond and DLC coatings, Curr. Opin. Solid State Mater. Sci. 22 (2018) 243-254. https://doi.org/10.1016/j.cossms.2018.11.003.

[7] W. Zhai, N. Srikanth, L.B. Kong, K. Zhou, Carbon nanomaterials in tribology, Carbon N. Y. 119 (2017) 150-171. https://doi.org/10.1016/j.carbon.2017.04.027.

[8] C. Muratore, A.A. Voevodin, Chameleon Coatings: Adaptive Surfaces to Reduce Friction and Wear in Extreme Environments, Annu. Rev. Mater. Res. 39 (2009) 297-324. https://doi.org/10.1146/annurevmatsci-082908-145259.

[9] V. Kupčík, L. Veselá-Nováková, Zur Kristallstruktur des Bismuthinits, $\mathrm{Bi}_{2} \mathrm{~S}_{3}, \mathrm{TMPM}$ Tschermaks Mineral. Und Petrogr. Mitteilungen. 14 (1970) 55-59. https://doi.org/10.1007/BF01081780.

[10] K. Łukaszewicz, J. Stępień-Damm, A. Pietraszko, A. Kajokas, J. Grigas, Crystal structure, thermal expansion, dielectric permittivity and phase transitions of $\mathrm{Bi}_{2} \mathrm{~S}_{3}$, Pol. J. Chem. 73 (1999) 541-546. 
[11] L.F. Lundegaard, E. Makovicky, T. Boffa-Ballaran, T. Balic-Zunic, Crystal structure and cation lone electron pair activity of $\mathrm{Bi}_{2} \mathrm{~S}_{3}$ between 0 and $10 \mathrm{GPa}$, Phys. Chem. Miner. 32 (2005) 578-584. https://doi.org/10.1007/s00269-005-0033-2.

[12] O. Rohr, Bismuth - the new ecologically green metal for modern lubricating engineering, Ind. Lubr. Tribol. 54 (2002) 153-164. https://doi.org/10.1108/00368790210431709.

[13] P. Gonzalez-Rodriguez, K.J.H. van den Nieuwenhuijzen, W. Lette, D.J. Schipper, J.E. ten Elshof, Tribochemistry of Bismuth and Bismuth Salts for Solid Lubrication, ACS Appl. Mater. Interfaces. 8 (2016) 7601-7606. https://doi.org/10.1021/acsami.6b02541.

[14] V.A. Krenev, N.F. Drobot, S. V. Fomichev, Bismuth: Reserves, applications, and the world market, Theor. Found. Chem. Eng. 49 (2015) 532-535. https://doi.org/10.1134/S0040579515040120.

[15] A. Begum, A. Hussain, A. Rahman, Optical and Electrical Properties of Doped and Undoped $\mathrm{Bi}_{2} \mathrm{~S}_{3}-\mathrm{PVA}$ Films Prepared by Chemical Drop Method, Mater. Sci. Appl. 02 (2011) 163-168. https://doi.org/10.4236/msa.2011.23020.

[16] P.R.R. Mesquita, J.S. Almeida, L.S.G. Teixeira, A.F. Da Silva, L.A. Silva, A fast sonochemical method to prepare 1D and 3D nanostructures of bismuth sulfide, J. Braz. Chem. Soc. 24 (2013) 280-284. https://doi.org/10.5935/0103-5053.20130036.

[17] H. Zhu, J. Hu, Y. Zhang, Y. Fei, Extreme Pressure Properties and Mechnism of Bismuth Naphthenate with Sulfur Containing Additives, in: Proc. Cist. ITS-IFToMM2008, Beijing, China, 2008: pp. 878-879.

[18] R.T. Hart, A. Kerr, N. Eckert, Bismuth Sulfide $\left(\mathrm{Bi}_{2} \mathrm{~S}_{3}\right)$ as the Active Species in Extreme Pressure Lubricants Containing Bismuth Carboxylates and Sulfur Compounds, Tribol. Trans. 53 (2010) 22-28. https://doi.org/10.1080/10402000903154816.

[19] J.Q. Hu, J. Zhu, K.Y. Gao, Y.W. Fei, Study on tribological properties of organic bismuth compounds as lubricationg additive, Adv. Mater. Res. 233-235 (2011) 1632-1635. https://doi.org/10.4028/www.scientific.net/AMR.233-235.1632.

[20] X. Xu, J. Hu, S. Yang, F. Xie, L. Guo, Extreme pressure synergistic mechanism of bismuth naphthenate and sulfurized isobutene, Surf. Rev. Lett. 24 (2017) 1-12. https://doi.org/10.1142/S0218625X17500718.

[21] C. Müller, F.L. Redondo, M. Dennehy, A.E. Ciolino, W.R. Tuckart, Bismuth (III) sulfide as additive: towards better lubricity without toxicity, Ind. Lubr. Tribol. 70 (2018) 347-352. https://doi.org/10.1108/ILT03-2017-0051.

[22] C. Müller, A.J. Avila, M. Denehy, M.J. Yañez, A.E. Ciolino, W. Tuckart, Morphological and tribological analysis of synthetic and commercial sulfures, Microsc. Microanal. 26 (2020) 115-116. https://doi.org/10.1017/s1431927620000793. 
[23] M.R. Vazirisereshk, A. Martini, D.A. Strubbe, M.Z. Baykara, Solid Lubrication with $\mathrm{MoS}_{2}$ : A Review, Lubricants. 7 (2019) 57. https://doi.org/10.3390/lubricants7070057.

[24] R. Holinski, J. Gänsheimer, A study of the lubricating mechanism of molybdenum disulfide, Wear. 19 (1972) 329-342.

[25] B. Vierneusel, T. Schneider, S. Tremmel, S. Wartzack, T. Gradt, Humidity resistant $\mathrm{MoS}_{2}$ coatings deposited by unbalanced magnetron sputtering, Surf. Coatings Technol. 235 (2013) 97-107. https://doi.org/10.1016/j.surfcoat.2013.07.019.

[26] E. Serpini, A. Rota, A. Ballestrazzi, D. Marchetto, E. Gualtieri, S. Valeri, The role of humidity and oxygen on $\mathrm{MoS}_{2}$ thin films deposited by RF PVD magnetron sputtering, Surf. Coatings Technol. 319 (2017) 345352. https://doi.org/10.1016/j.surfcoat.2017.04.006.

[27] X. Zhao, G. Zhang, L. Wang, Q. Xue, The Tribological Mechanism of $\mathrm{MoS}_{2}$ Film under Different Humidity, Tribol. Lett. 65 (2017) 1-8. https://doi.org/10.1007/s11249-017-0847-3.

[28] I.L. Singer, R.N. Bolster, J. Wegand, S. Fayeulle, B.C. Stupp, Hertzian stress contribution to low friction behavior of thin MoS $_{2}$ coatings, Appl. Phys. Lett. 57 (1990) 995-997. https://doi.org/10.1063/1.104276.

[29] C. Donnet, J.M. Martin, T. Le Mogne, M. Belin, The origin of super-low friction coefficient of $\mathrm{MoS}_{2}$ coatings in various environments, Tribol. Ser. 27 (1994) 277-284. https://doi.org/10.1016/S01678922(08)70317-1.

[30] A.K. Kohli, B. Prakash, Contact pressure dependency in frictional behavior of burnished molybdenum disulphide coatings, Tribol. Trans. 44 (2001) 147-151. https://doi.org/10.1080/10402000108982439.

[31] T. Liang, W.G. Sawyer, S.S. Perry, S.B. Sinnott, S.R. Phillpot, First-principles determination of static potential energy surfaces for atomic friction in $\mathrm{MoS}_{2}$ and $\mathrm{MoO}_{3}$, Phys. Rev. B - Condens. Matter Mater. Phys. 77 (2008) 1-6. https://doi.org/10.1103/PhysRevB.77.104105.

[32] T. Onodera, Y. Morlta, A. Suzuki, M. Koyama, H. Tsuboi, N. Hatakeyama, A. Endou, H. Takaba, M. Kubo, F. Dassenoy, C. Minfray, L. Joly-Pottuz, J.M. Martin, A. Miyamoto, A computational chemistry study on friction of h-MoS 2 . Part I. Mechanism of single sheet lubrication, J. Phys. Chem. B. 113 (2009) 1652616536. https://doi.org/10.1021/jp9069866.

[33] T. Onodera, Y. Morita, R. Nagumo, R. Miura, A. Suzuki, H. Tsuboi, N. Hatakeyama, A. Endou, H. Takaba, F. Dassenoy, C. Minfray, L. Joly-Pottuz, M. Kubo, J.M. Martin, A. Miyamoto, A computational chemistry study on friction of h-MoS2. Part II. Friction anisotropy, J. Phys. Chem. B. 114 (2010) 15832-15838. https://doi.org/10.1021/jp1064775.

[34] G. Levita, A. Cavaleiro, E. Molinari, T. Polcar, M.C. Righi, Sliding properties of MoS $_{2}$ layers: Load and interlayer orientation effects, J. Phys. Chem. C. 118 (2014) 13809-13816. 
https://doi.org/10.1021/jp4098099.

[35] G. Levita, P. Restuccia, M.C. Righi, Graphene and $\mathrm{MoS}_{2}$ interacting with water: A comparison by ab initio calculations, Carbon N. Y. 107 (2016) 878-884. https://doi.org/10.1016/j.carbon.2016.06.072.

[36] G. Levita, M.C. Righi, Effects of Water Intercalation and Tribochemistry on $\mathrm{MoS}_{2}$ Lubricity: An Ab Initio Molecular Dynamics Investigation, ChemPhysChem. 18 (2017) 1475-1480. https://doi.org/10.1002/cphc.201601143.

[37] T. Arif, S. Yadav, G. Colas, C.V. Singh, T. Filleter, Understanding the Independent and Interdependent Role of Water and Oxidation on the Tribology of Ultrathin Molybdenum Disulfide $\left(\mathrm{MoS}_{2}\right)$, Adv. Mater. Interfaces. 6 (2019) 1-9. https://doi.org/10.1002/admi.201901246.

[38] P.K. Chow, E. Singh, B.C. Viana, J. Gao, J. Luo, J. Li, Z. Lin, A.L. Elías, Y. Shi, Z. Wang, M. Terrones, N. Koratkar, Wetting of mono and few-layered WS2 and $\mathrm{MoS}_{2}$ films supported on $\mathrm{Si} / \mathrm{SiO}_{2}$ substrates, ACS Nano. 9 (2015) 3023-3031. https://doi.org/10.1021/nn5072073.

[39] I.L. Singer, A thermochemical model for analyzing low wear-rate materials, Surf. Coatings Technol. 49 (1991) 474-481. https://doi.org/10.1016/0257-8972(91)90103-4.

[40] E.Y.A. Wornyoh, C.F. Higgs, R. Pudjoprawoto, On the influence of friction on velocity at a powderlubricated slider-disk interface: Experimentation, in: Proc. STLE/ASME 2010 Int. Jt. Tribol. Conf., San Francisco, (2010) 1-3.

[41] H. Wang, J.J. Zhu, J.M. Zhu, H.Y. Chen, Sonochemical method for the preparation of bismuth sulfide nanorods, J. Phys. Chem. B. 106 (2002) 3848-3854. https://doi.org/10.1021/jp0135003.

[42] L. Greenspan, Humidity fixed points of binary saturated aqueous solutions, J. Res. Natl. Bur. Stand. (1934). 81A (1977) 89-96.

[43] P. Hohenberg, W. Kohn, Inhomogeneous electron gas physical review 136, B864. (1964).

[44] W. Kohn, L.J. Sham, Self-consistent equations including exchange and correlation effects, Phys. Rev. 140 (1965) A1133.

[45] G. Levita, M.C. Righi, Effects of Water Intercalation and Tribochemistry on $\mathrm{MoS}_{2}$ Lubricity: An Ab Initio Molecular Dynamics Investigation, ChemPhysChem. 18 (2017) 1475-1480. https://doi.org/10.1002/cphc.201601143.

[46] H.S. Khare, D.. Burris, Surface and Subsurface Contributions of Oxidation and Moisture to Room Temperature Friction of Molybdenum Disulfide, Tribol. Lett. 53 (2014) 329-336. https://doi.org/10.1007/s11249-013-0273-0. 
[47] H.S. Khare, D.. Burris, The Effects of Environmental Water and Oxygen on the Temperature-Dependent Friction of Sputtered Molybdenum Disulfide, Tribol. Lett. 52 (2013) 485-493.

https://doi.org/10.1007/s11249-013-0233-8.

[48] G. Kresse, J. Furthmüller, Efficient iterative schemes for ab initio total-energy calculations using a plane-wave basis set, Phys. Rev. B. 54 (1996) 11169.

[49] G. Kresse, D. Joubert, From ultrasoft pseudopotentials to the projector augmented-wave method, Phys. Rev. B. 59 (1999) 1758.

[50] P.E. Blöchl, Projector augmented-wave method, Phys. Rev. B. 50 (1994) 17953.

[51] J.P. Perdew, K. Burke, M. Ernzerhof, Generalized gradient approximation made simple, Phys. Rev. Lett. 77 (1996) 3865.

[52] P.K. Panigrahi, A. Pathak, The Growth of Bismuth Sulfide Nanorods from Spherical-Shaped Amorphous Precursor Particles under Hydrothermal Condition, J. Nanoparticles. 2013 (2013) 1-11. https://doi.org/10.1155/2013/367812.

[53] T.W. Scharf, P.G. Kotula, S. V. Prasad, Friction and wear mechanisms in $\mathrm{MoS}_{2} \mathrm{Sb}_{2} \mathrm{O}_{2} \mathrm{Au}$ nanocomposite coatings, Acta Mater. 58 (2010) 4100-4109. https://doi.org/10.1016/j.actamat.2010.03.040.

[54] R.L. Fusaro, Lubrication and failure mechanisms of molybdenum disulfide films. II: Effect of substrate roughness, NASA Technical Paper 1379, (1978) 1-31.

[55] T.W. Scharf, S. V. Prasad, Solid lubricants: A review, J. Mater. Sci. 48 (2013) 511-531. https://doi.org/10.1007/s10853-012-7038-2.

[56] S. Fayeulle, P.D. Ehni, I.L. Singer, Analysis of transfer films formed on steel and Co-WC during sliding against $\mathrm{MoS}_{2}$-coated steel in argon, Surf. Coat. Technol. 41 (1990) 93-101.

[57] K.J. Wahl, I.L. Singer, Quantification of a lubricant transfer process that enhances the sliding life of a $\mathrm{MoS}_{2}$ coating, Tribol. Lett. 1 (1995) 59-66. https://doi.org/10.1007/BF00157976.

[58] Z. Nishiyama, Martensitic transformation, Elsevier, 2012.

[59] T. Böker, R. Severin, A. Müller, C. Janowitz, R. Manzke, D. Voß, P. Krüger, A. Mazur, J. Pollmann, Band structure of $\mathrm{MoS}_{2}, \mathrm{MoSe}_{2}$, and a-MoTe : Angle-resolved photoelectron spectroscopy and ab initio calculations, Phys. Rev. B. 64 (2001) 235305.

[60] W. Li, J. Carrete, N. Mingo, Thermal conductivity and phonon linewidths of monolayer $\mathrm{MoS}_{2}$ from first principles, Appl. Phys. Lett. 103 (2013) 253103. 


\section{Figures}
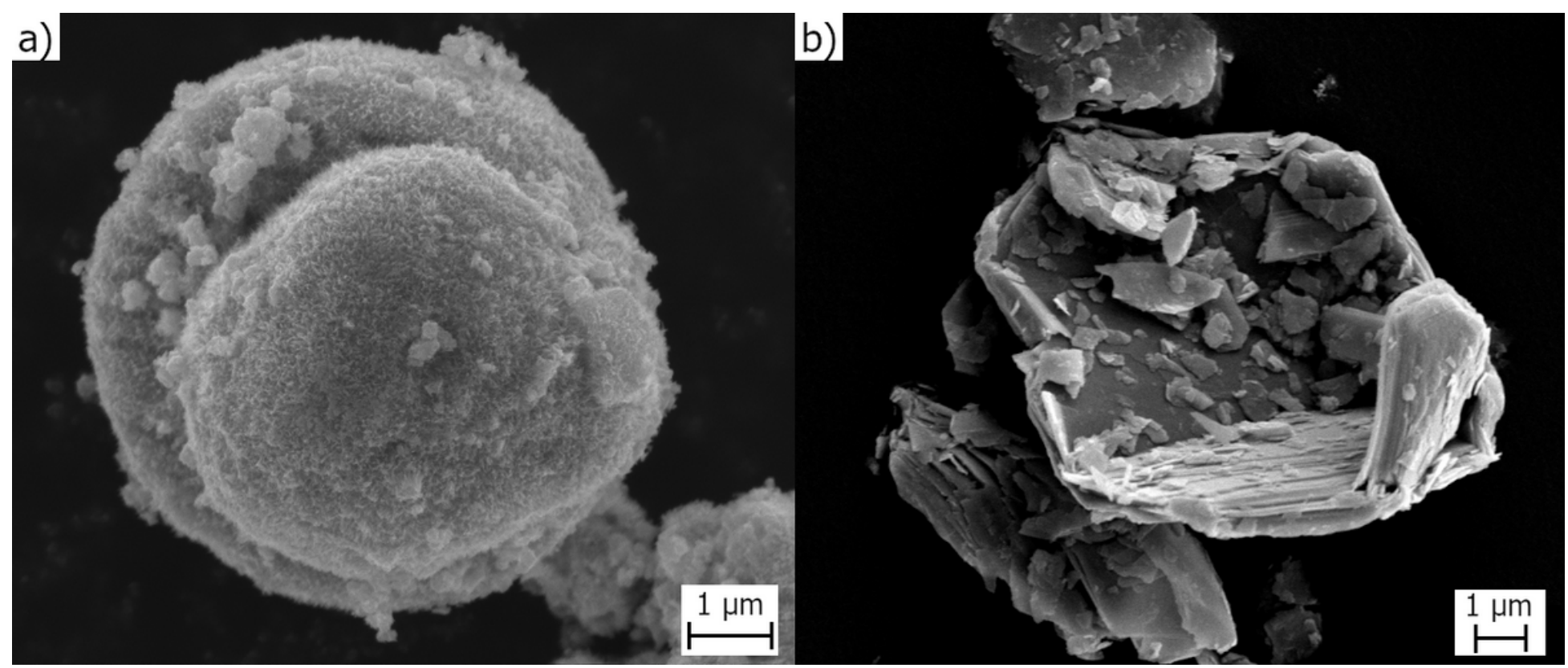

\section{Figure 1}

SEM images of a) Bi2S3 and b) MoS2.
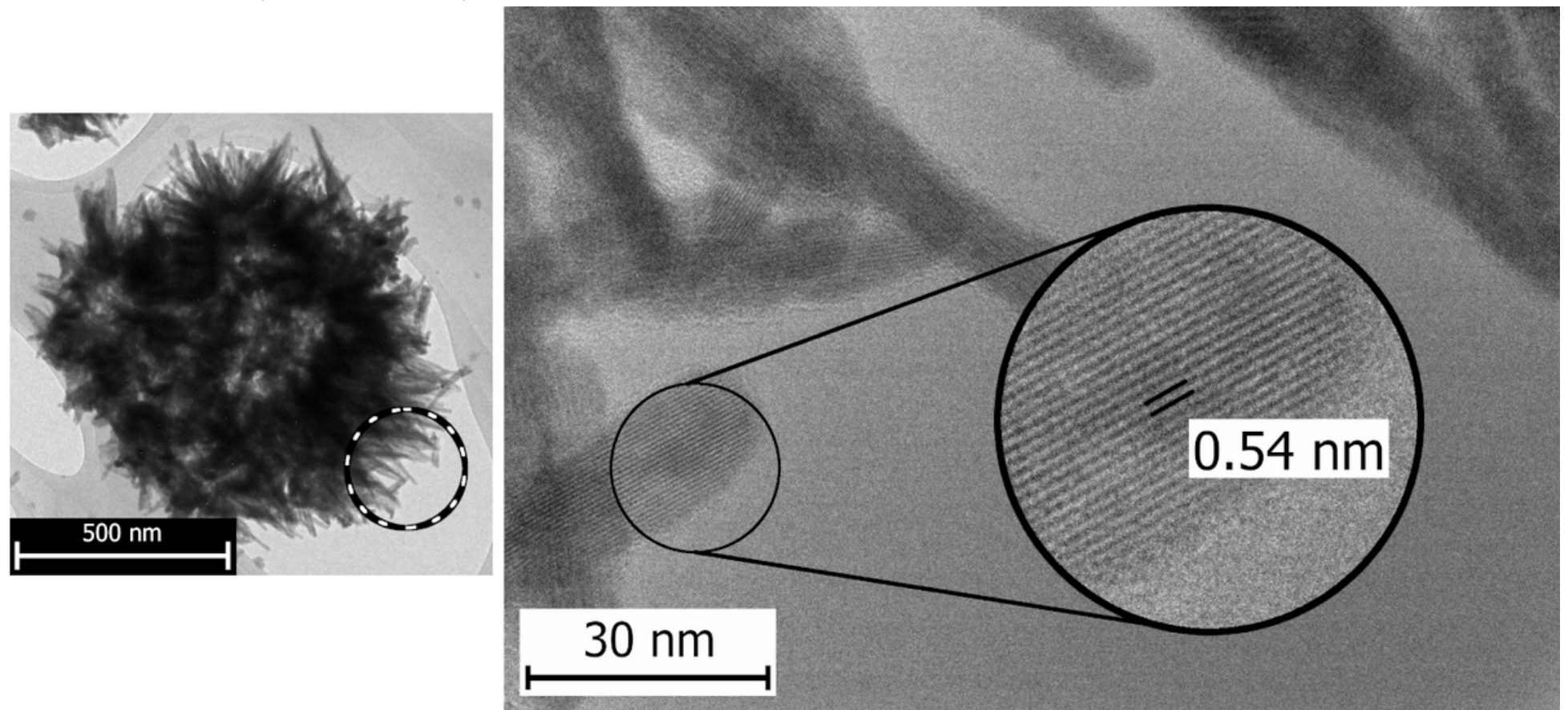

Figure 2

TEM image of an agglomeration of Bi2S3 nanorods (left) and a detail of the highlighted region, showing nanorods with average diameters of $10 \mathrm{~nm}$, lengths between 30 to $100 \mathrm{~nm}$, and a fringe distance of 0.54 $\mathrm{nm}$. 

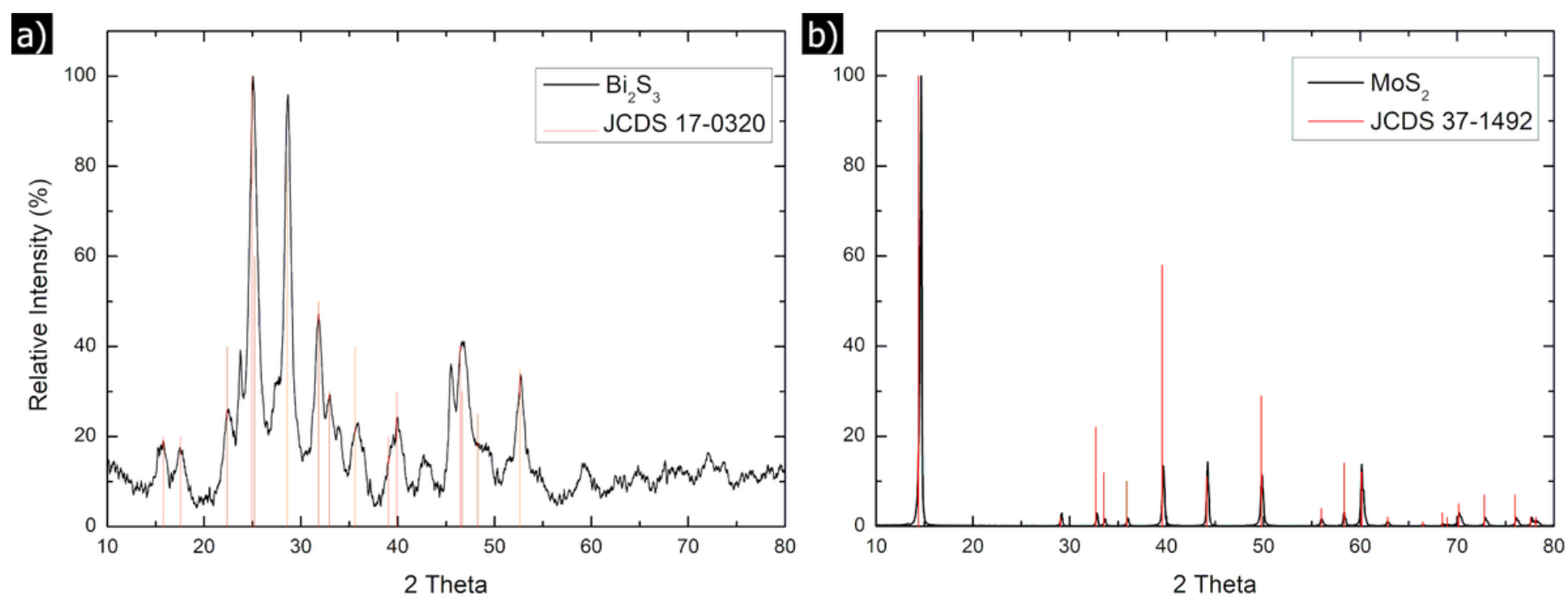

Figure 3

XRD spectra of a) Bi2S3 and b) MoS2.
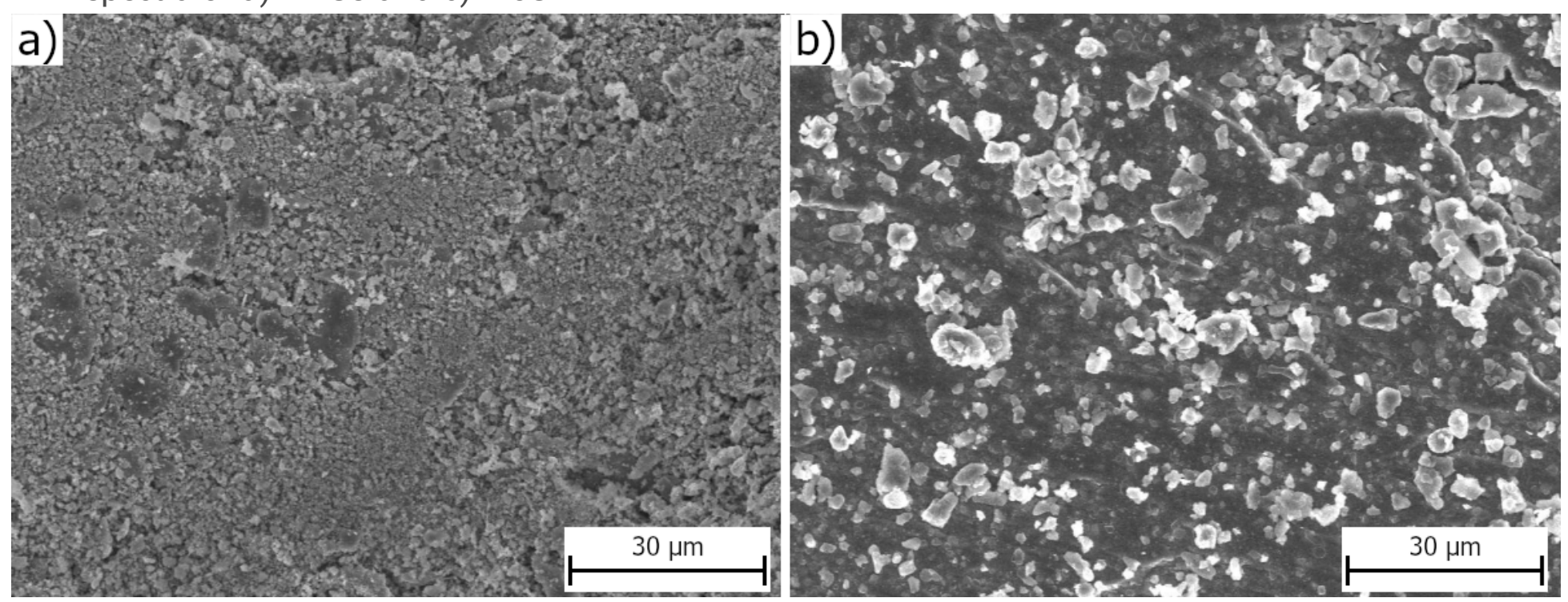

Figure 4

SEM image of a) Bi2S3 and b) MoS2 soft coatings prepared by burnishing. 

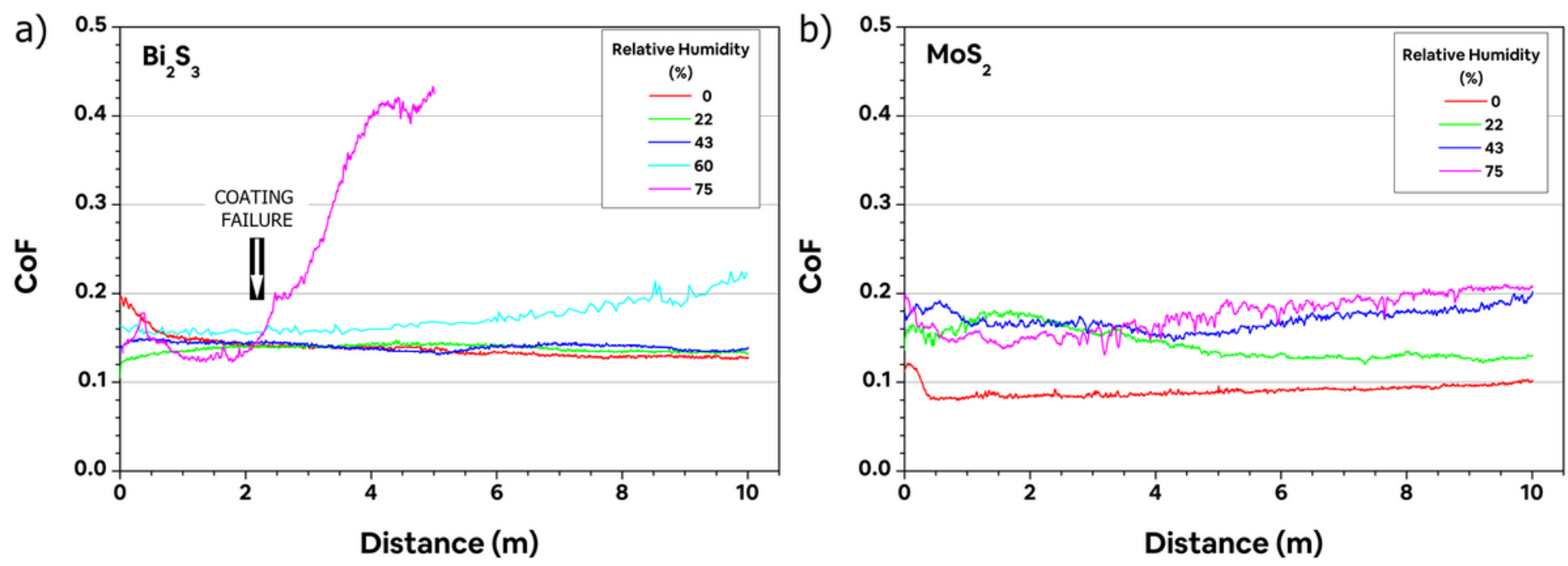

Figure 5

Friction records for a) Bi2S3 and b) MoS2 coatings under variable relative humidity levels. In all cases, the contact stress was $0.8 \mathrm{GPa}$ and the sliding speed $10 \mathrm{~mm} / \mathrm{s}$.
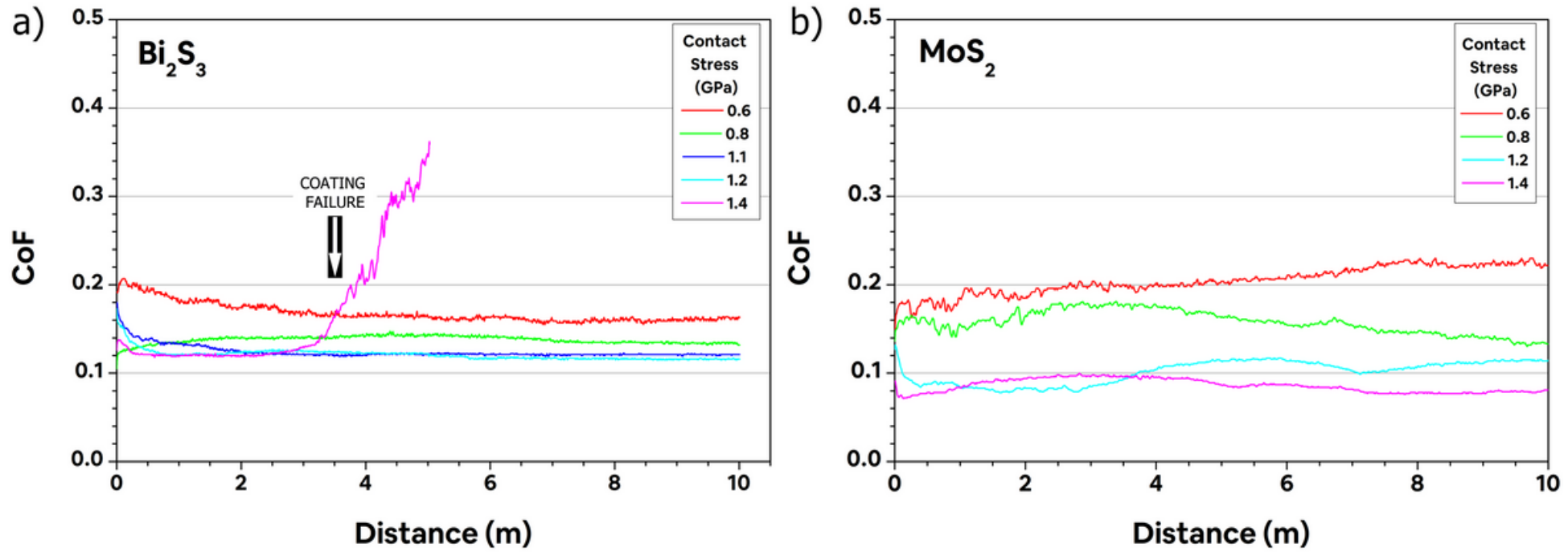

Figure 6

Friction records for a) Bi2S3 and b) MoS2 coatings under variable contact stress levels. In all cases, the humidity level was $22 \%$ and the sliding speed $10 \mathrm{~mm} / \mathrm{s}$. 

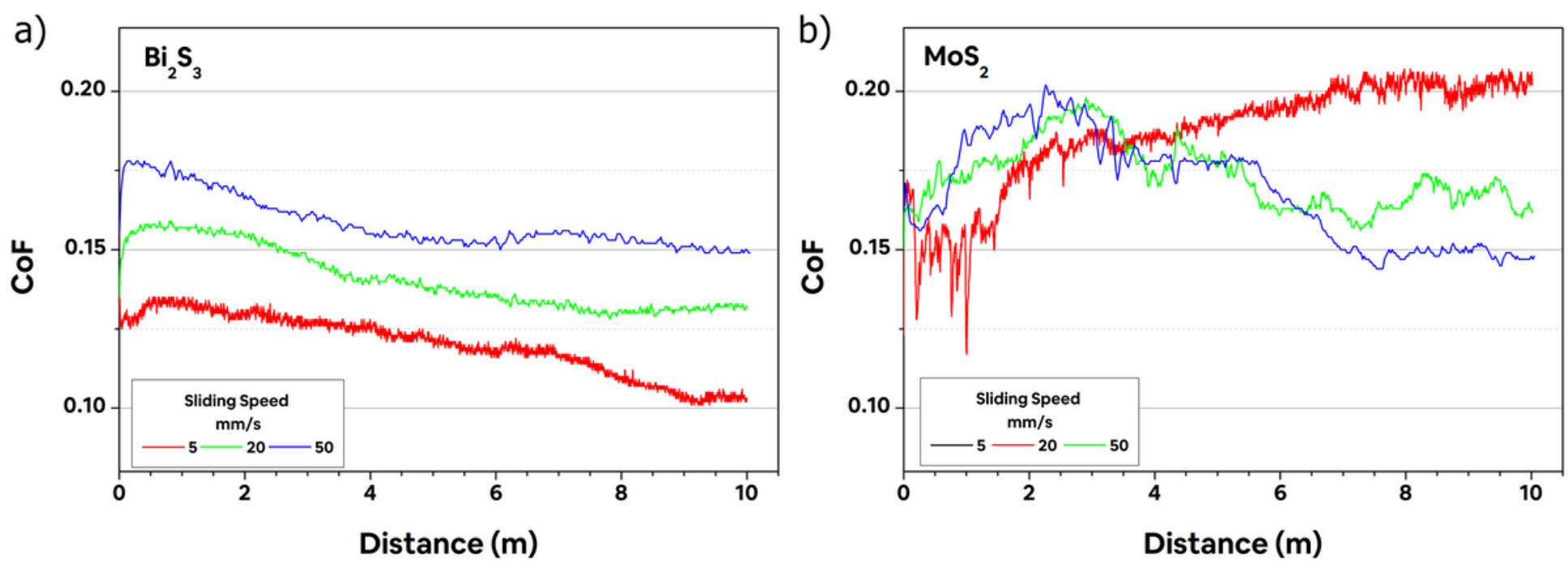

Figure 7

Friction records for a) Bi2S3 and b) MoS2 coatings under variable sliding speeds. In all cases, the humidity level was $22 \%$ and the contact stress was $0.8 \mathrm{GPa}$.
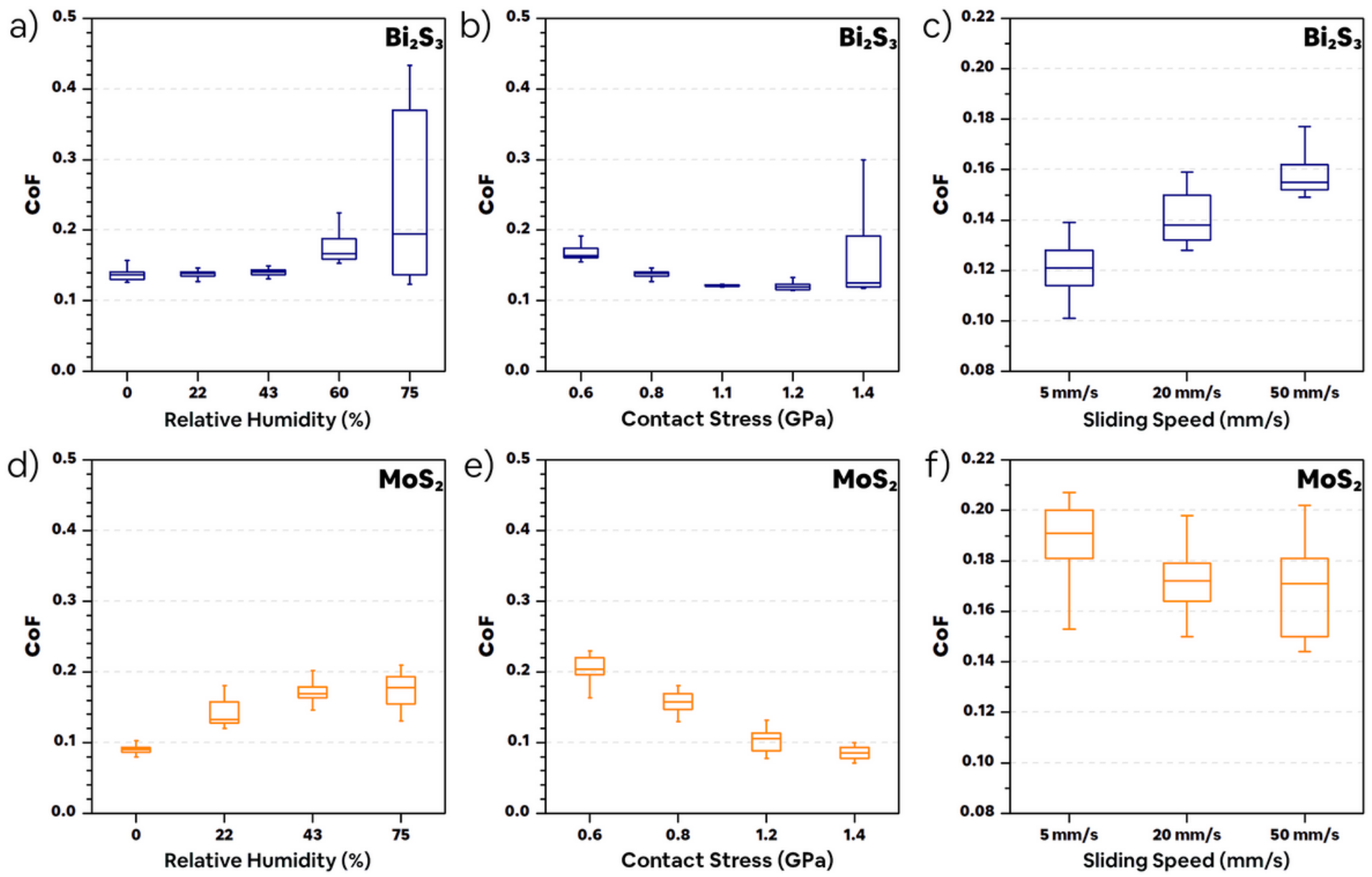

Figure 8

Summary of friction results. 
SEM

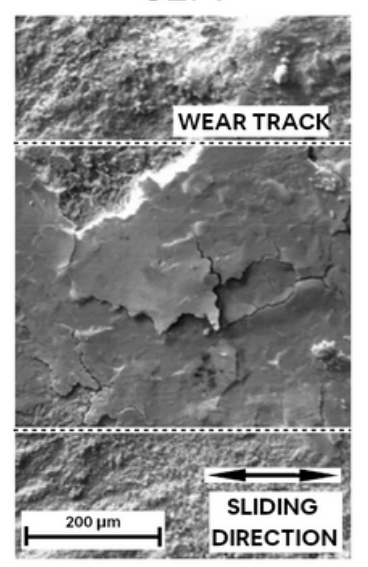

$\mathrm{Bi}$

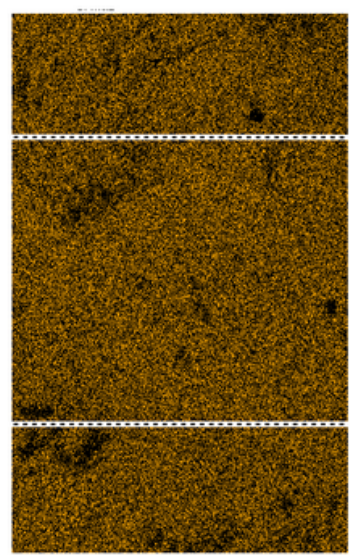

S

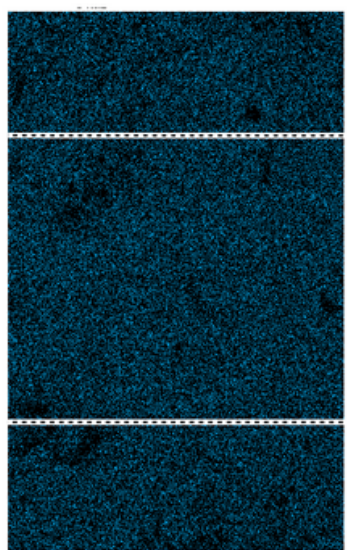

$\mathrm{Fe}$

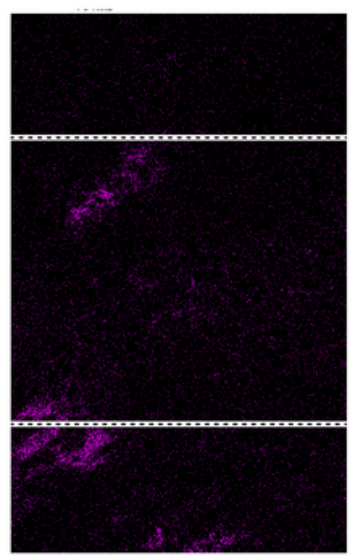

$\mathrm{O}$

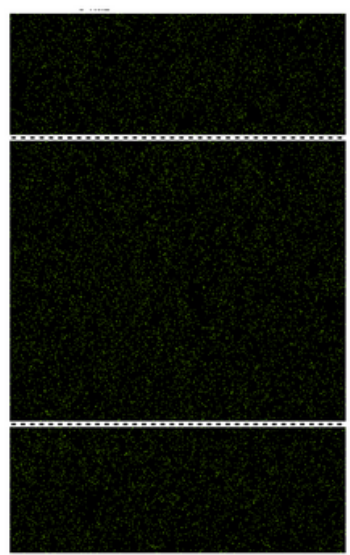

\section{Figure 9}

SEM-EDS mapping of the wear track after testing a Bi2S3 coating at $0.6 \mathrm{GPa}$ of contact stress and $22 \%$ of relative humidity. 


\section{SEM}

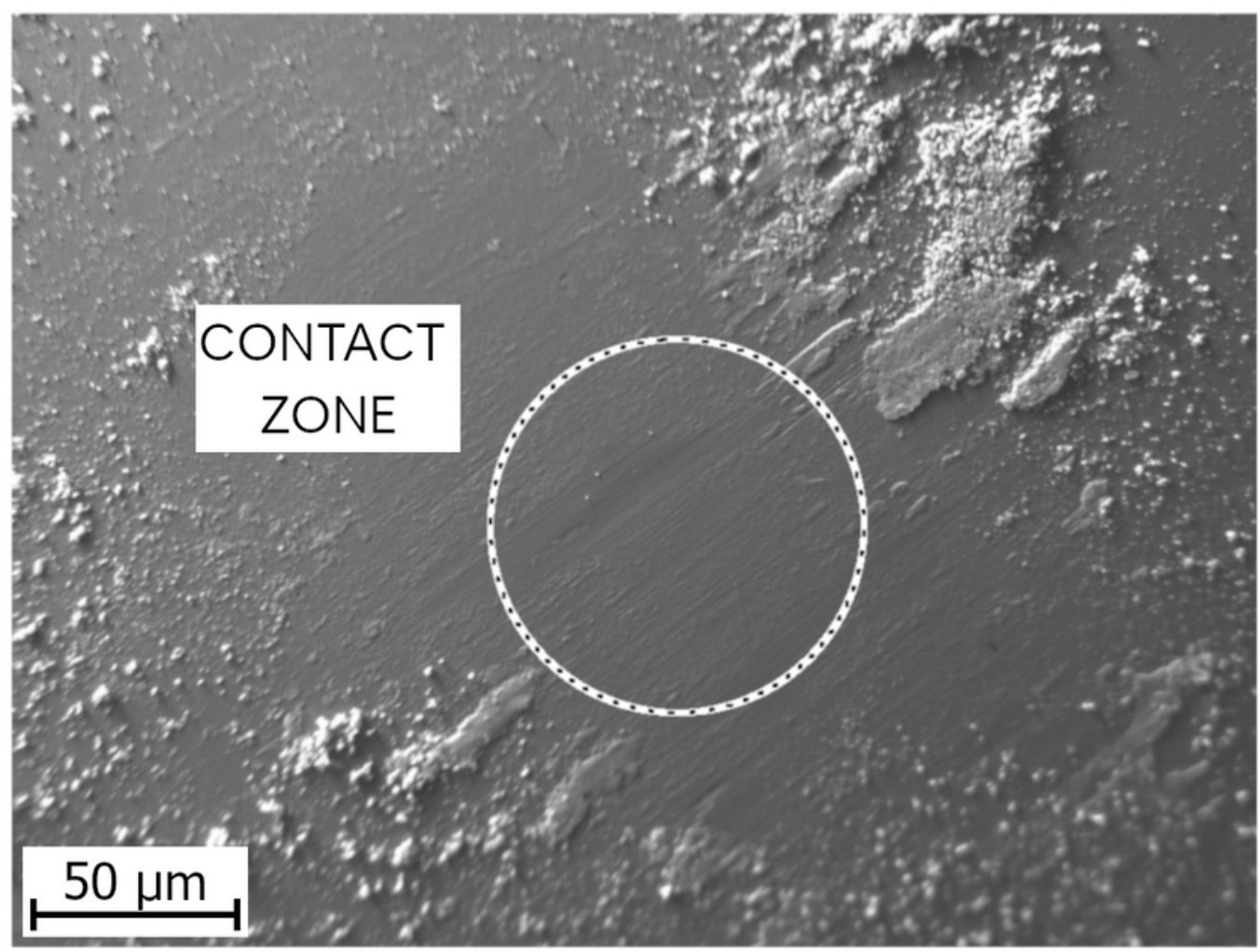

\section{Elemental Mapping}

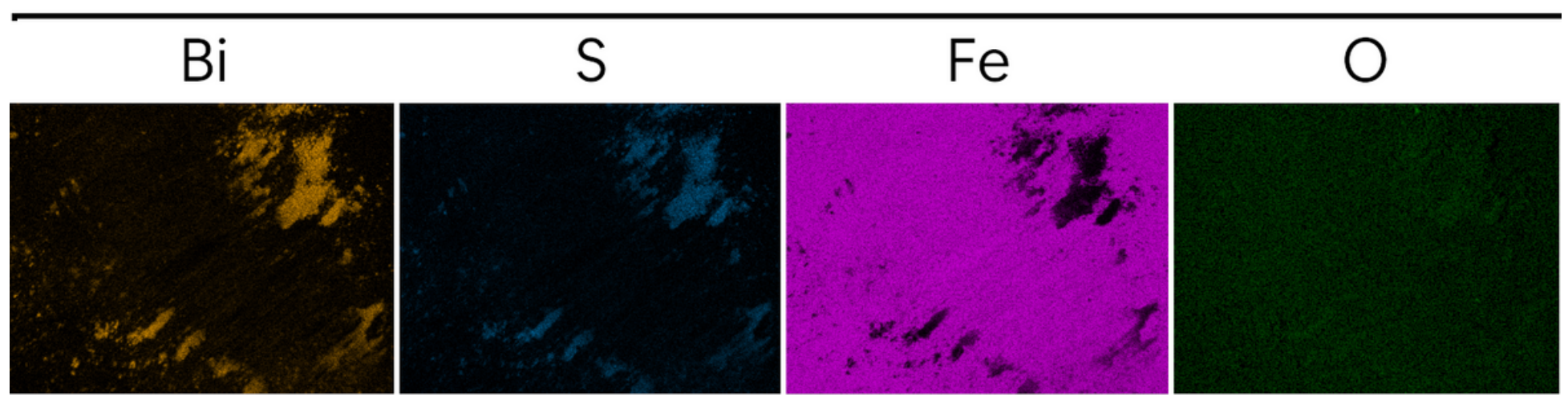

Figure 10

SEM-EDS mapping of the AISI 52100 counterpart after testing a Bi2S3 coating at $0.6 \mathrm{GPa}$ of contact stress and $22 \%$ of relative humidity. 

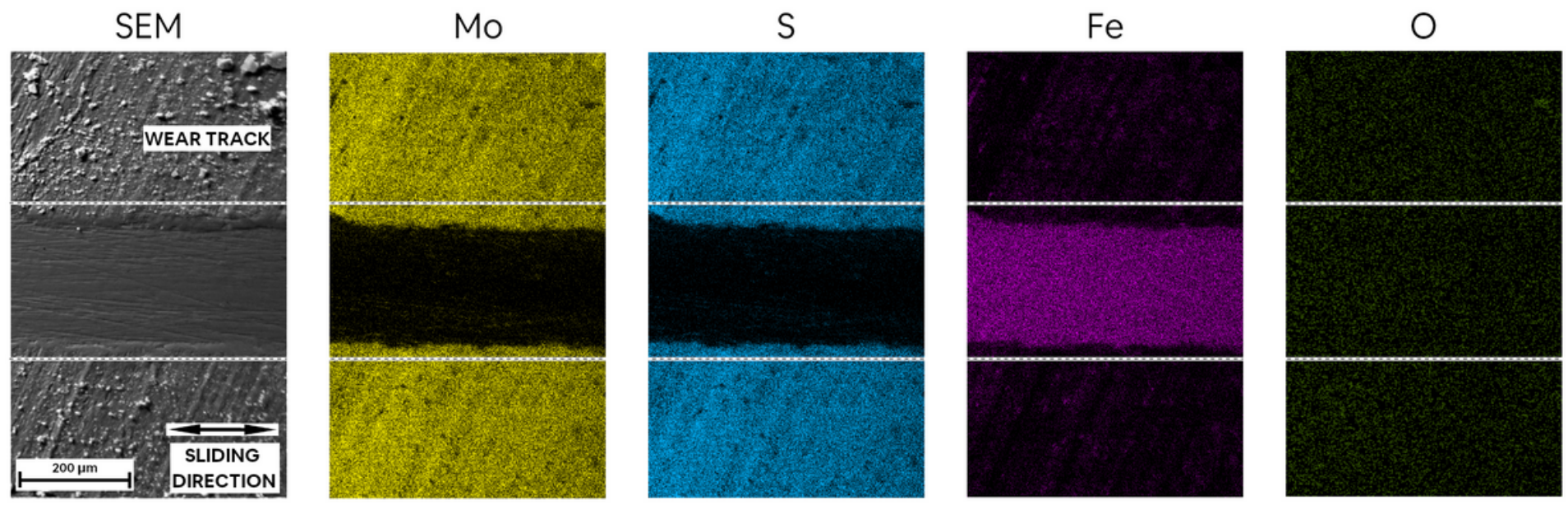

Figure 11

SEM-EDS mapping of the wear track after testing a MoS2 coating at $0.6 \mathrm{GPa}$ of contact stress and $22 \%$ of relative humidity. 


\section{SEM}

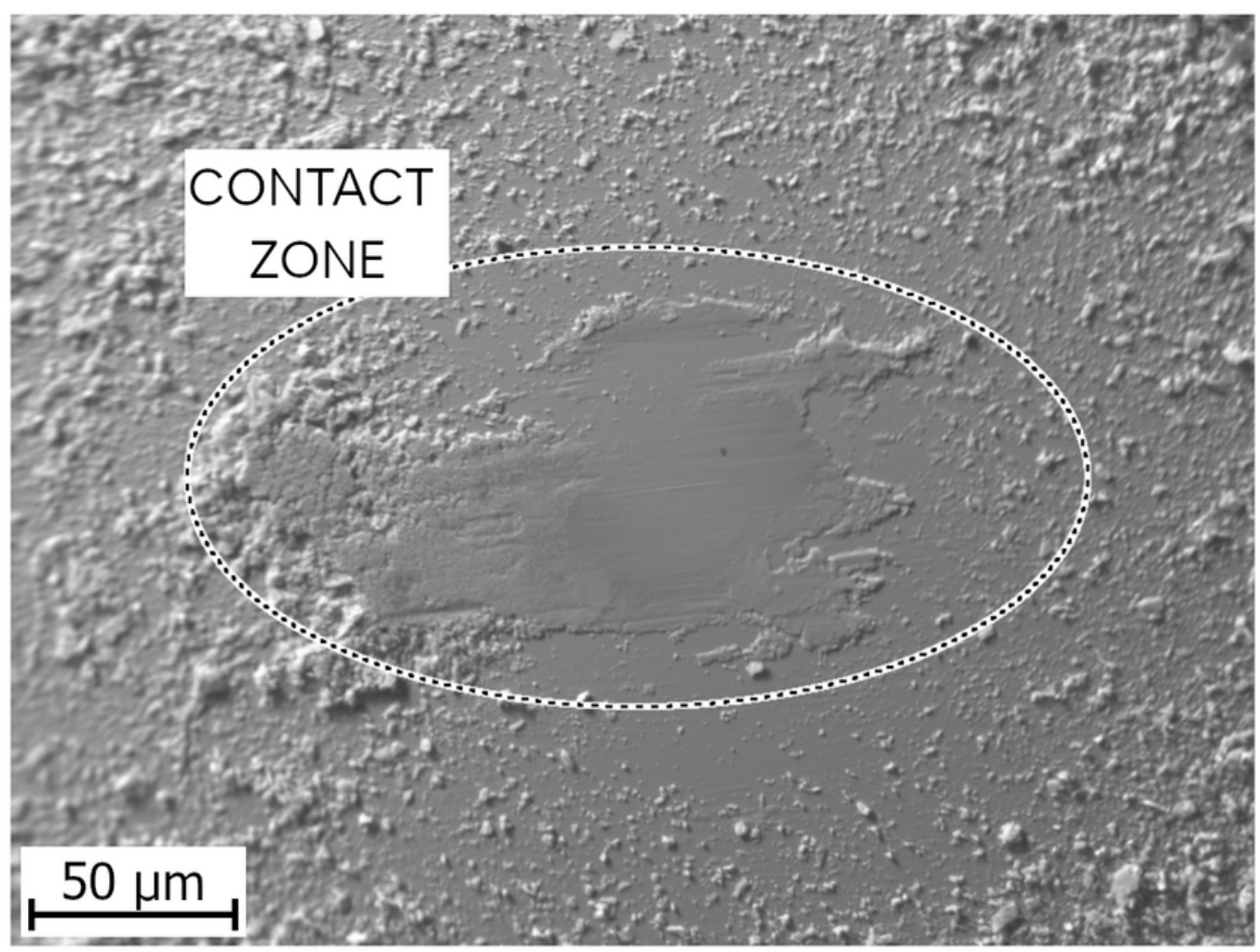

\section{Elemental Mapping}

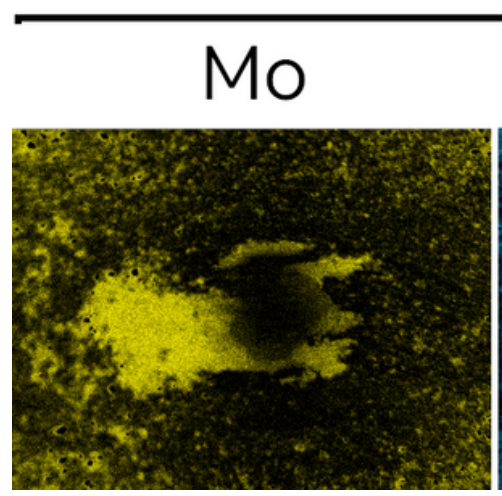

\section{S}

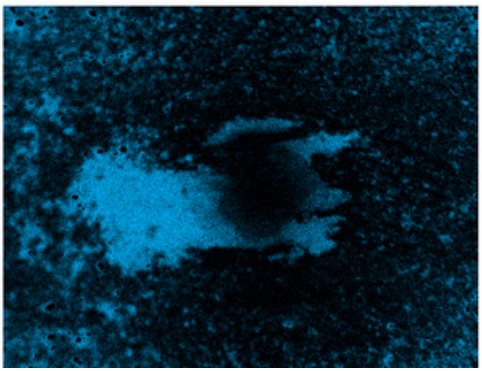

$\mathrm{Fe}$

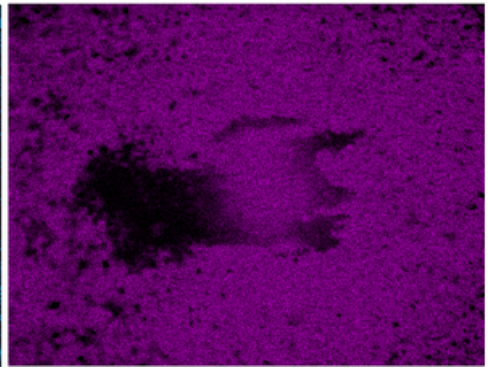

$\mathrm{O}$

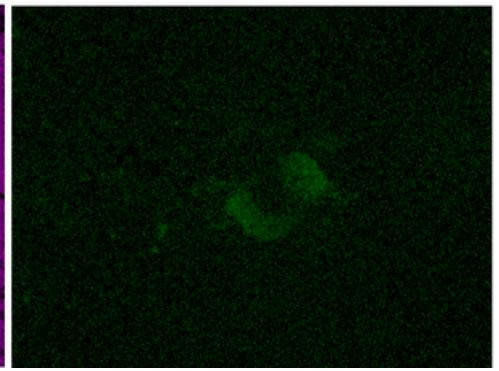

Figure 12

SEM-EDS mapping of the AISI 52100 counterpart after testing a MoS2 coating at $0.6 \mathrm{GPa}$ of contact stress and $22 \%$ of relative humidity. 

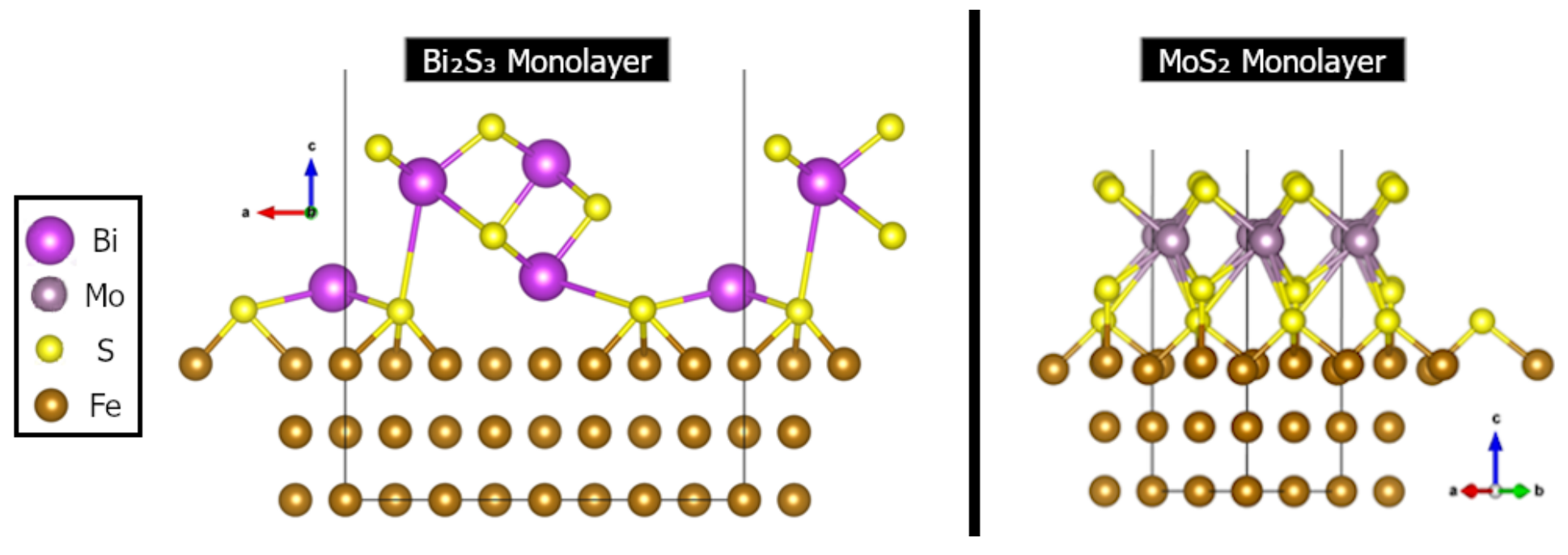

Figure 13

DFT Model of Bi2S3 and MoS2 monolayers interacting with a Fe slab to evaluate the adhesion energies. 

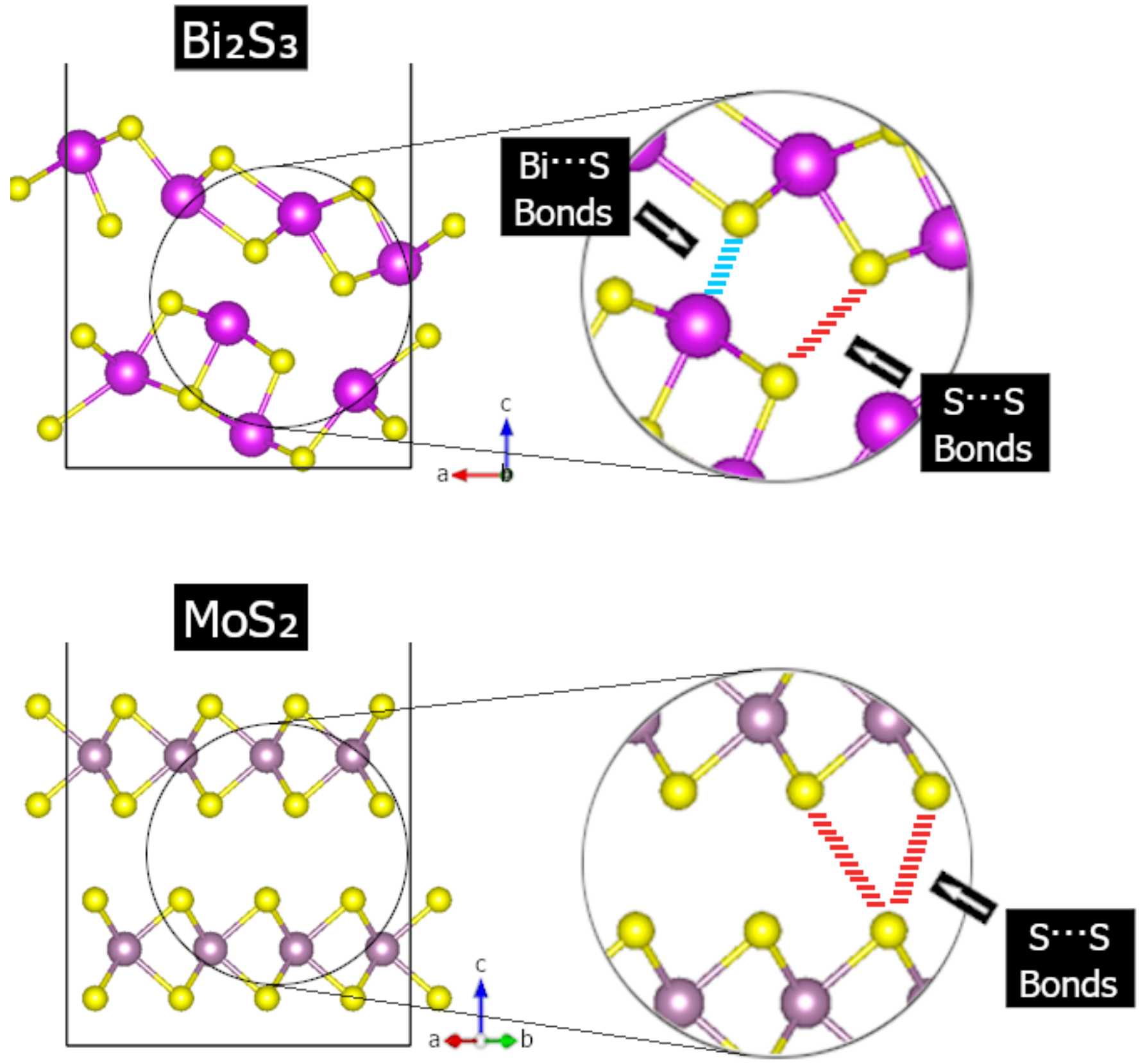

Figure 14

DFT setup of the sulfide supercells and detail of the atomic interactions. 


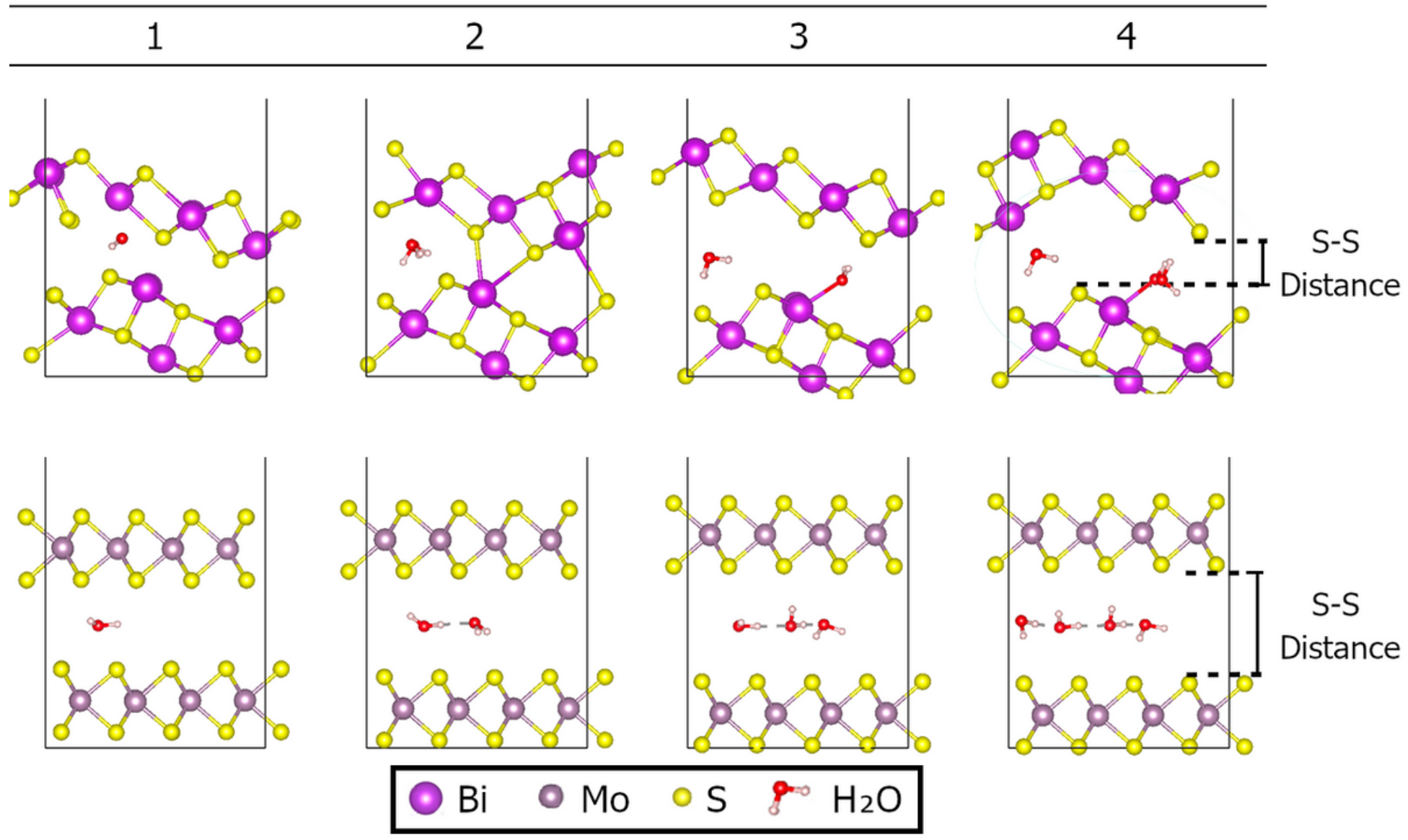

Figure 15

DFT modeling of the sulfide supercells with added $\mathrm{H} 2 \mathrm{O}$ molecules. 


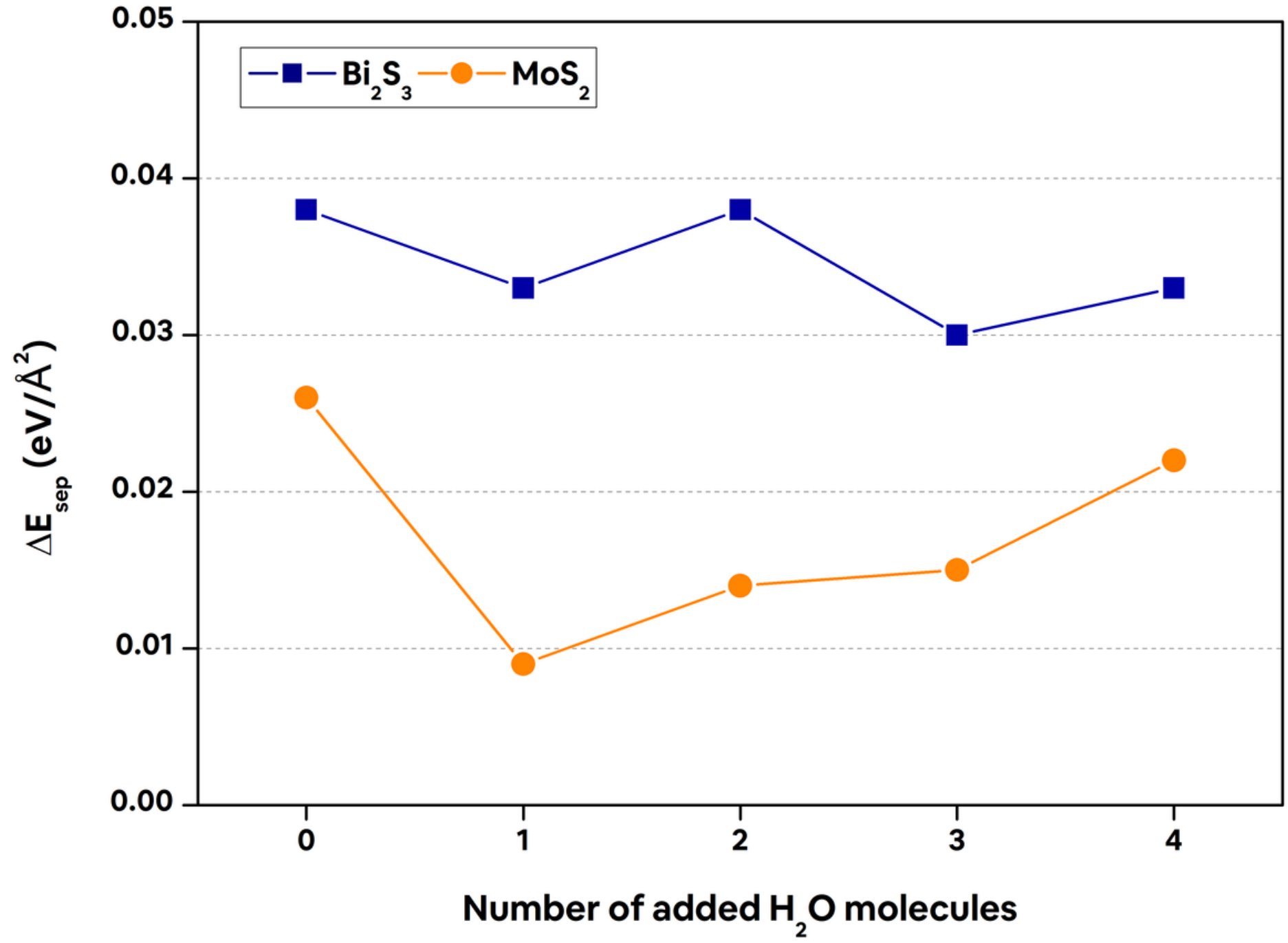

Figure 16

Variation of $\Delta$ Esep as a function of the added number of $\mathrm{H} 2 \mathrm{O}$ molecules. 


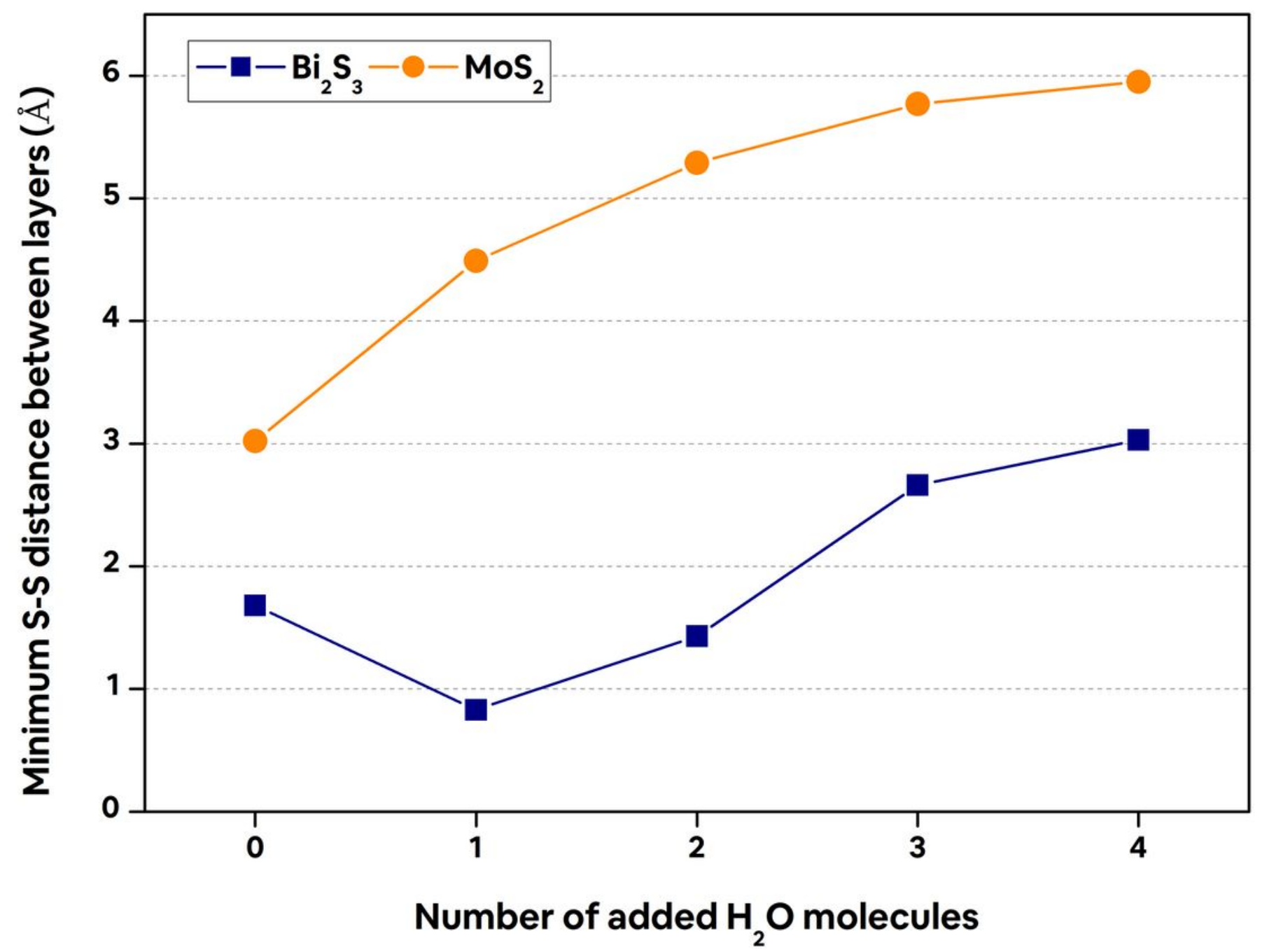

Figure 17

Shortest distance between the $\mathrm{S}$ atoms of each sulfide layer as a function of the amount of $\mathrm{H} 2 \mathrm{O}$ molecules added to the system. 


\section{$\mathrm{Bi}_{2} \mathrm{~S}_{3}+3 \mathrm{H}_{2} \mathrm{O}$}
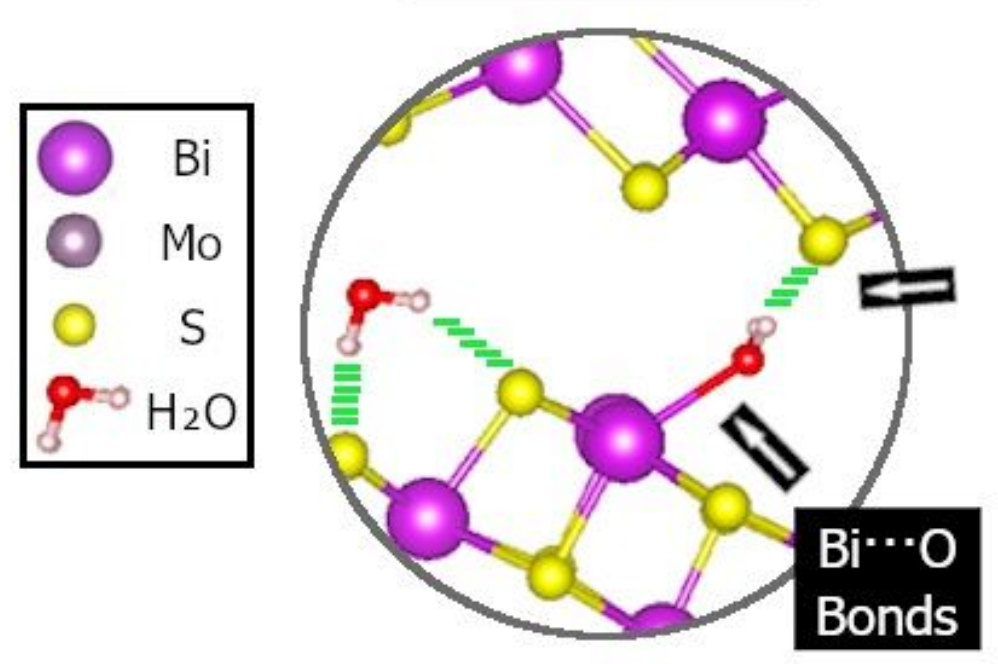

$\mathrm{MoS}_{2}+3 \mathrm{H}_{2} \mathrm{O}$

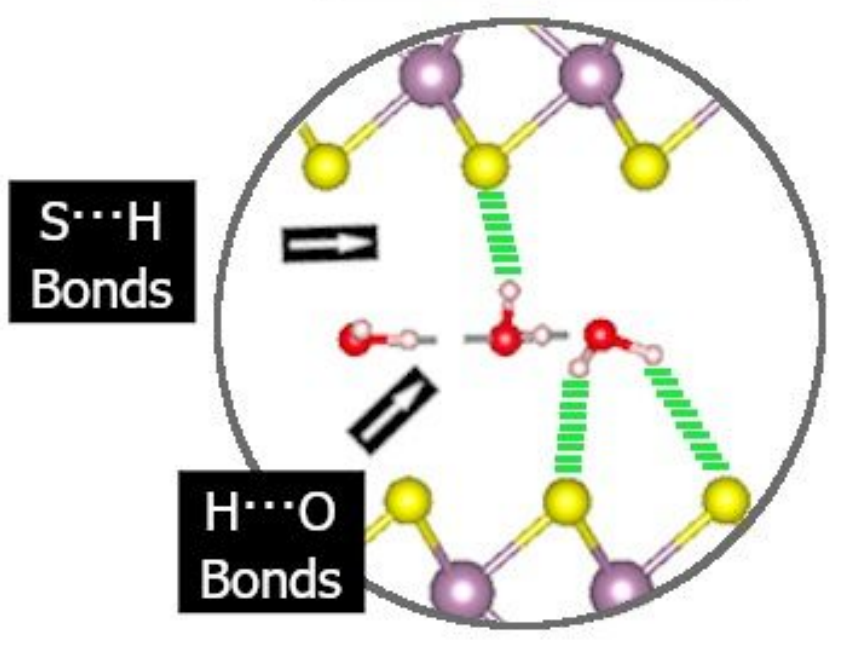

Figure 18

Detail of the interactions between the sulfide layers and three $\mathrm{H} 2 \mathrm{O}$ molecules.

\section{Supplementary Files}

This is a list of supplementary files associated with this preprint. Click to download.

- SupplementaryMaterial.pdf 